Modeling, Identification and Control, Vol. 40, No. 2, 2019, pp. 89-108, ISSN 1890-1328

\title{
Enabling Energy Savings in Offshore Mechatronic Systems by using Self-Contained Cylinders
}

\author{
Daniel Hagen ${ }^{1}$ Damiano Padovani ${ }^{1}$ Martin Choux ${ }^{1}$ \\ ${ }^{1}$ Department of Engineering Sciences, University of Agder, N-4898 Grimstad, Norway. \\ E-mail: daniel.hagen@uia.no
}

\begin{abstract}
This paper proposes a novel actuation system for an offshore drilling application. It consists of three self-contained electro-hydraulic cylinders that can share and store regenerated energy. The energy saving potential of the proposed solution is analyzed through a multibody system simulation. The self-contained system demonstrates superior energy efficiency compared to the benchmark system representing the stateof-the-art approach used today (i.e., valve-controlled cylinders by means of pressure-compensated directional control valves and counter-balance valves, supplied by a centralized hydraulic power unit). Due to the "power on demand" capability, the cancellation of the throttling losses, and the opportunity to recover energy in motoring quadrants, the self-contained system consumes $83.44 \%$ less energy without affecting the system's performance.
\end{abstract}

Keywords: Electrification of hydraulics, linear actuator, offshore mechatronic systems, self-contained electro-hydraulic cylinder, proportional directional control valve, passive load-holding, energy savings

\section{Introduction}

With the increasing focus on the environmental impact, such as $\mathrm{CO}_{2}$ emission and hydraulic fluid pollution, of the oil and gas industry, traditionally used hydraulically-actuated systems tend to be replaced by electric drives (Pawlus et al., 2016). However, force densities available from linear hydraulic actuators are still typically higher than those of electric actuators. Therefore, after the electrification of all rotational actuations, hydraulic power is still needed to actuate some hydraulic cylinders controlled by throttling valves. A relevant Offshore Mechatronic System (OMS) example is the pipe handling equipment (Fig. 1) implemented on state-of-the-art drilling rigs (Bak, 2014), where AC motors with a variable speed drive and a gearbox, here referred to as AC drivetrains, have successfully replaced all hydraulic motors. However, for some of the linear actuators included in the operational motion cycle, hydraulic Valve-Controlled
Cylinders (VCCs) are still state-of-the-art, although an electro-mechanical counterpart has been used in other industry fields for many years. For electro-mechanical cylinders, the predominant challenges are low reliability under high load operating conditions. In Hagen et al. (2017) an offshore case-study was carried out, demonstrating that the permissible transmitted power of the most promising available off-the-shelf electromechanical cylinder was lower than the power required by the motion cycle of the existing hydraulic actuation system. Typically in OMSs, the hydraulic source is supplied from a centralized Hydraulic Power Unit (HPU) consisting of multiple pumps driven by large electric motors. The required electric power is generated by diesel generators that are running continuously, supplying the entire offshore installation with electricity.

An alternative solution to the inefficient VCC is a "valve-less" pump controlled (electro-hydraulic) cylinder drive. Pump-controlled concepts using standard 
differential cylinders are classified and reviewed in Ketelsen et al. (2019). In literature, research related to compact electro-hydraulic cylinders is primarily on cost efficiency and low power applications (less than $5[k W])$. In this paper, these solutions are referred to as Self-Contained Cylinders (SCCs), namely selfsufficient and sealed systems that only consume energy when motion is demanded. For instance, Michel and Weber (2012) derived specific conclusions about the best approach for SCCs. However, passive loadholding capability was not considered. An alternative approach based on a triple pump solution which enables higher stiffness and good energy efficiency was also considered (Schmidt et al., 2015, 2017; Ketelsen et al., 2018). However, the hydraulic circuits of typically offshore load-carrying applications must contain passive load-holding devices to meet safety regulations. Hence, a literature survey and simulation study of an SCC concept that can operate in four quadrants, including passive load holding, suitable for power levels above $5[k W]$, is presented in Hagen et al. (2018). In Padovani et al. (2019), a similar SCC concept, also including a filter and cooling circuit, was successfully implemented on a single-boom crane and tested in two quadrant operations; the proper functioning of the passive load-holding capability and an overall energy efficiency of about $60 \%$ during actuation were demonstrated. Therefore, applying such a drive technology to a multi-actuator OMS and demonstrating the resulting benefits over the more traditional valve-controlled hydraulic cylinders is the target of this investigation.

To fully benefit from the great energy efficiency of SCCs, the entire operation cycle of a pipe handling equipment with periods of motoring, load holding and regenerative braking must be considered together with different solutions for storing energy. Inspired by the principles introduced and explained in Ristic and Wahler (2018), this paper proposes an actuation system consisting of three SCCs that can share energy with other electric-drives and store regenerated energy in a battery, instead of using brake resistors to dissipate the recovered energy as heat to the surrounding.

Section (2) presents the offshore drilling application case study. A conventional offshore VCC system used as a benchmark is explained in Section (3) whereas the proposed SCC system is addressed in Section (4). Section (5) contains an inverse dynamic analysis of the energy recovery potential of the case study, and identifies the design requirements for the actuation systems. Furthermore, it presents the simulated system performance, power consumption, energy efficiency, and a comparison of the two actuation systems regarding the energy consumption. Finally, section (6) discusses the simulation results and some practical challenges that must be considered in future works.

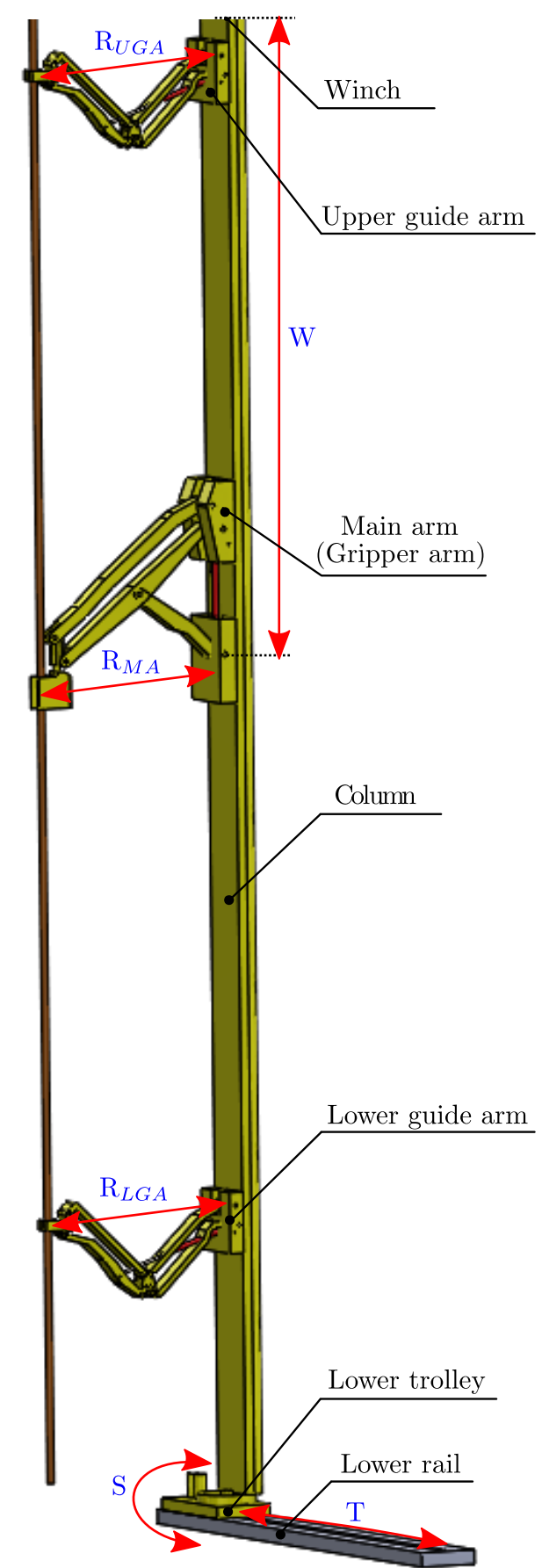

Figure 1: Considered offshore mechatronic system (simplified CAD model of the multibody system).

\section{The Considered Case-Study}

An offshore Pipe Racking Machine (PRM), as shown in Fig. 1, is used as an OMS case study for analyzing the energy saving potential when replacing the cen- 
tralized VCCs of the reach arms (i.e., the upper guide arm, the main arm, and the lower guide arm) with SCCs. The PRM is a column-type multipurpose pipe handling machine (drill-pipe, drill-collar and casings) that combines the functionality of several traditional types of pipe handling equipment in one machine.

The PRM can perform the following tasks according to Hagen et al., 2017:

- moving stands (two or more joints of pipe connected) between the Well Center (WC) and the desired Finger Board (FB) slot

- building of stands for storage inside the FB while drilling

- handling of a single pipe from horizontal to vertical position and vice versa

- lifting operation on drill floor, i.e., the main arm can be used as a crane.

By rack and pinion systems, the column is supported at the upper beam (not shown) and at the lower rail. The lower rail is mounted directly on the drill floor, whereas the upper beam is connected to the structure of the derrick. The column includes an upper and a lower Guide Arm (GA) that are designed to guide the stand, i.e., guide the top and bottom of the drill-stand being in motion. The arm located in the middle is the Main Arm (MA), responsible for holding the pipe in a secure grip (gripper arm). All arms are equipped with a VCC which allows for the extension and retraction (i.e., horizontal Reach (R) motion) in order to position a stand in the desired FB slot or at the WC. Redundant $\mathrm{AC}$ drivetrains are located both on the upper and lower Trolleys (T), controlling the horizontal movement of the column along the tracks. The Winch (W) located on top of the column is used to hoist and lower the MA (i.e., the stand) using redundant AC drivetrains. Finally, the redundant AC drivetrains located on the lower trolley make it possible for the column to Slew (S) (rotate) about its vertical axis.

\subsection{The Considered Operation Sequence}

The operation sequence considered in this study is the so-called tripping sequence. It takes place when the drill-string is assembled or disassembled during a wellconstruction process. During this sequence, the PRM continually moves between the WC and the FB where the stands are stored. The leading specification rating of these machines is the tripping speed, i.e., how many stands can be moved between the WC and the FB per hour. The motion steps of the PRM for the considered sequence are illustrated in Fig. 2.
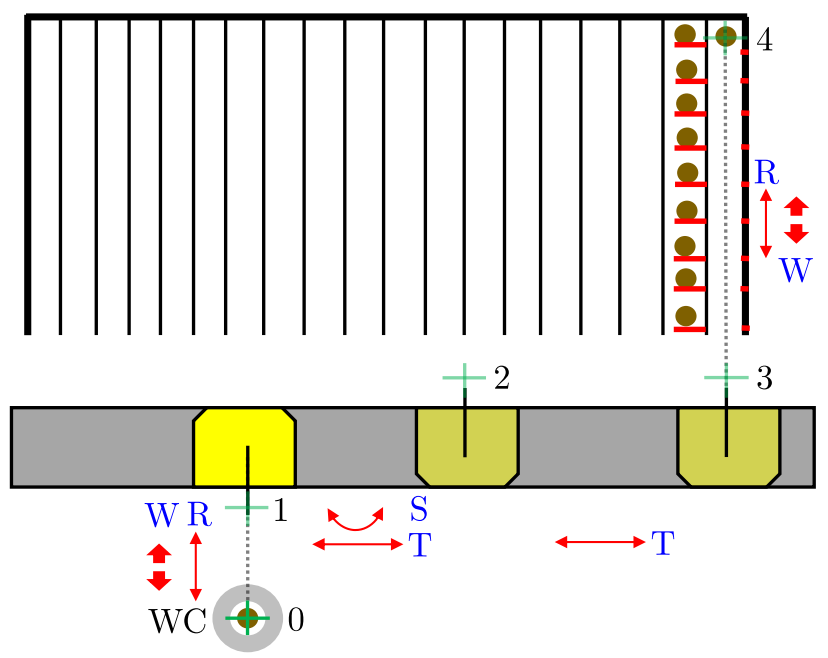

Figure 2: Operation sequence steps of the arms reach $(\mathrm{R})$, winch $(\mathrm{W})$, trolley $(\mathrm{T})$, and slew $(\mathrm{S})$, when moving a drill-stand from the well-center to the desired fingerboard slot (simplified top-view).

The PRM starts at the $\mathrm{WC}$ and a stand is ready for being moved to the desired FB slot. The sequence consists of the following steps:

0-1; the MA gripper and GAs guide close around the stand, the winch lifts the MA (the stand) for $1[\mathrm{~m}]$ and the arms retract from the WC position to the inner reach position

$1-2$; the PRM starts to trolley and rotates $180\left[^{\circ}\right]$

2-3; the PRM continues to trolley until reaching the set-point (a $9[\mathrm{~m}]$ traveling is performed)

$3-4$; the three arms extend until the set-point of $4[\mathrm{~m}]$ is reached, the stand is lowered for $2[\mathrm{~m}]$ to the floor, and the MA gripper and GAs guide open while the machine returns back to $\mathrm{WC}$ in reverse steps.

\subsection{Motion Reference Generator}

An motion profile with a constant jerk S-curve, represented by a second-order polynomial function in velocity ( $3^{r d}$ order in position), is used for all motion references. As an example, a motion profile for the MA cylinder extending and retracting is shown in Fig. 3 for position set-point $x_{C_{S P}}=400[\mathrm{~mm}]$, velocity setpoint $v_{C_{S P}}=120\left[\frac{\mathrm{mm}}{\mathrm{s}}\right]$, and acceleration set-point $a_{C_{S P}}=80\left[\frac{\mathrm{mm}}{\mathrm{s}^{2}}\right]$.

The maximum jerk is found as:

$$
j_{C_{S P}}=\frac{a_{C_{S P}}^{2}}{v_{C_{S P}}-v_{C_{0}}} .
$$




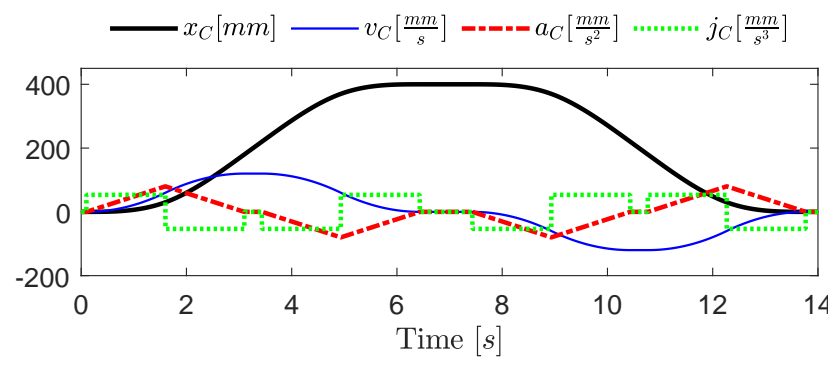

Figure 3: Main arm cylinder motion profile example.

The time period with constant velocity necessary to reach the desired position may be estimated as:

$$
t_{c s t}=\frac{x_{C_{S P}}-2 s_{a}}{v_{C_{S P}}}
$$

where

$$
s_{a}=\frac{v_{C_{S P}}-v_{C_{0}}}{a_{C_{S P}}}
$$

is the travel distance during the acceleration phase.

\subsubsection{Reach Arm Kinematics}

During the considered operation cycle, the reach motion (position $\left(x_{R}\right)$ and velocity $\left(v_{R}\right)$ ) of the MA and of the GAs must be operated synchronously when the stand is moved. The main control input are depicted in Fig. 4, for defining the desired motion reference (i.e., cylinder position and the velocity) of the MA cylinder. Furthermore, the GAs follow the calculated reach motion based on the desired MA cylinder motion trajectory.

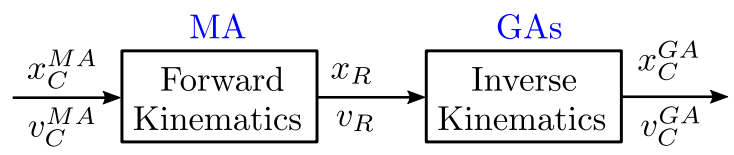

Figure 4: Reach arms motion reference conversion.

The reach length/position of the MA with respect to the effective cylinder stroke length $\left(x_{C}^{M A}\right)$, i.e., the forward kinematics, is derived using the Pythagoras theorem, as illustrated in Fig. 5, and calculated as:

$$
x_{R}=\underbrace{\sqrt{c^{2}-a^{2}}}_{b}+x_{R_{0}}
$$

where $c$ (the hypotenuse) is the known length of the arm, $a$ (the opposite side) is the sum of effective cylinder displacement and the cylinder's initial length $\left(a=x_{C}^{M A}+x_{C_{0}}^{M A}\right)$, and $x_{R_{0}}$ is the offset from the revolute joint $\left(R J_{b c}\right)$ to the center of the pipe. The reach velocity is calculated as:

$$
v_{R}=-\frac{a}{b} v_{C}^{M A}
$$

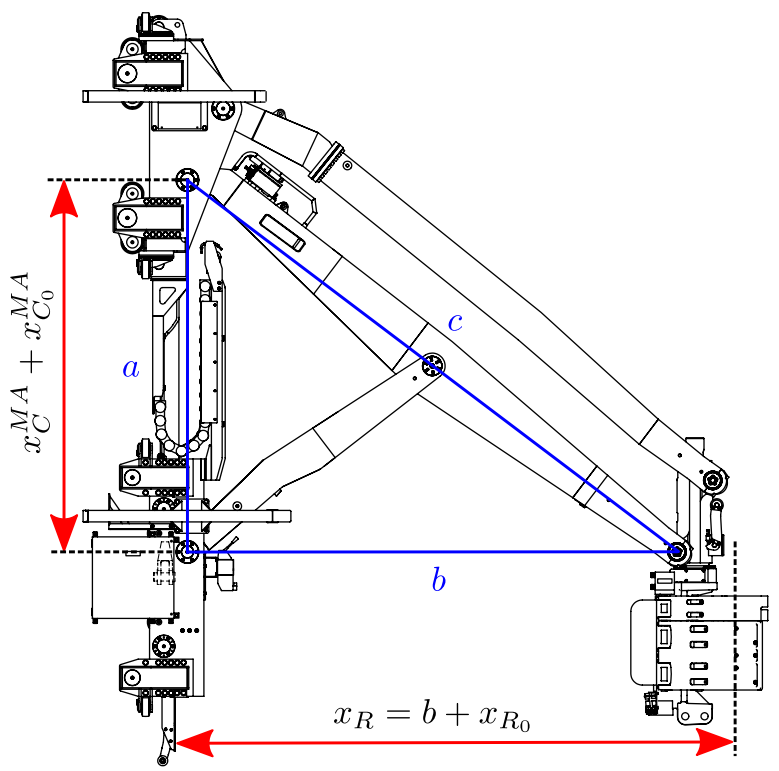

Figure 5: Main arm at max reach $\left(x_{R}=4[m]\right.$ and $x_{C}^{M A}=$ $0[m])$.

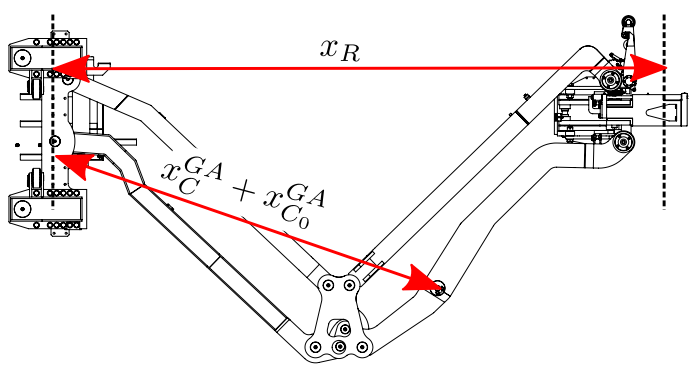

Figure 6: Guide arm at max reach $\left(x_{R}=4[\mathrm{~m}]\right.$ and $x_{C}^{G A}=$ $1.04[m])$.

An efficient solvable analytical expression is not obtained for the GA's inverse kinematics with sufficient accuracy because of the height variation of the tool point when the mechanism extends or retract. Hence, the required cylinder positions of the GAs $\left(x_{C}^{G A}\right)$, as illustrated in Fig. 6, to follow the desired reach position are calculated using the polynomial function:

$$
x_{C}^{G A}=p_{5} x^{5}+p_{4} x^{4}+p_{3} x^{3}+p_{2} x^{2}+p_{1} x+p_{0}
$$

where $x$ is the input (reach position) minus an offset $\left(x=x_{R}-x_{R_{0}}^{G A}\right)$, and $p_{0 \ldots 5}$ are coefficients identified using curve fitting on simulated position values of $x_{R}$ and $x_{C}^{G A}$. The maximum error between the reference position and the measured reach position is $1[\mathrm{~mm}]$ (i.e., below $0.04 \%$ of the total reach length). Finally, the velocity of the GAs cylinders are calculated as:

$$
v_{C}^{G A}=\left(5 p_{5} x^{4}+4 p_{4} x^{3}+3 p_{3} x^{2}+2 p_{2} x+p_{5} x\right) v_{R} .
$$




\subsection{Multibody System Model}

The mechanical system of the PRM is modeled using the multibody system (MBS) library in MATLABSimulink@. The MBS is modeled based on the work in Hagen et al. (2017), where a similar MBS of the MA is mathematically represented and simulated. In this paper, in addition to the MA (consisting of 9 bodies, a payload and 8 RJs), two GAs (consisting of $2 \cdot 10$ bodies and $2 \cdot 12$ RJs), the column (1 body), the lower trolley (1 body), and the lower rail (1 body) are modeled, as shown in Fig. 7, to simulate the considered operation sequence. The input of the MBS model depends on if an inverse or forward dynamic analysis is carried out. Either the desired position reference is used as an input and the output force/torque is analyzed (inverse dynamics), or the force/torque from the actuation system model (e.g., the hydraulic force from the cylinders) is used as input to the actuated joints and the output motion are analyzed (forward dynamics).

\subsubsection{Friction Models}

The combined friction $\left(F_{f}^{i}\right)$ of both the actuator (i.e., the hydraulic cylinders and the AC drivetrains) and the mechanical system (i.e., the revolute joints) is modeled according to an equivalent Stribeck model:

$$
F_{f}^{i}=f_{v}^{i} \dot{x}+\tanh (\dot{x} a)\left(F_{C}^{i}+f_{S}^{i} e^{-\frac{\dot{x} \tanh (\dot{x} a)}{\tau_{S}}}\right)
$$

where $\dot{x}$ is the velocity of the $i^{\text {th }}$ actuator, $a$ is the constant value used in the tanh function, while the different coefficients account the viscous friction $\left(f_{v}^{i}\right)$, the Coulomb friction $\left(F_{C}^{i}\right)$, the static friction $\left(f_{S}^{i}\right)$ and the friction force's constant $\left(\tau_{S}=0.02\left[\frac{\mathrm{s}}{\mathrm{m}}\right]\right)$. The parameters used for each actuator are listed in Table 1 . In case of rotary motions, the angular velocity is used, resulting in a friction torque $\left(T_{f}^{i}\right)$.

Table 1: Friction parameters.

\begin{tabular}{llll}
\hline Actuator & $f_{v}^{i}$ & $F_{C}^{i}$ & $f_{S}^{i}$ \\
\hline$F_{f}^{M A}:$ & $60\left[\frac{k N s}{m}\right]$ & $1.13[k N]$ & $1.25[k N]$ \\
$F_{f}^{G A}:$ & $20\left[\frac{k N s}{m}\right]$ & $0.38[k N]$ & $0.75[k N]$ \\
$F_{f}^{W}:$ & $30\left[\frac{k N s}{m}\right]$ & $0.56[k N]$ & $0.88[k N]$ \\
$F_{f}^{T}:$ & $40\left[\frac{k N s}{m}\right]$ & $0.75[k N]$ & $0.1[k N]$ \\
$T_{f}^{S}:$ & $16[k N s]$ & $0.30[k N m]$ & $0.05[k N m]$ \\
\hline
\end{tabular}

\subsection{Specifications}

The PRM consists of four main degrees of freedom, as highlighted in Figs. 1-2. In Table 2 the requirements for the considered actuators are described.

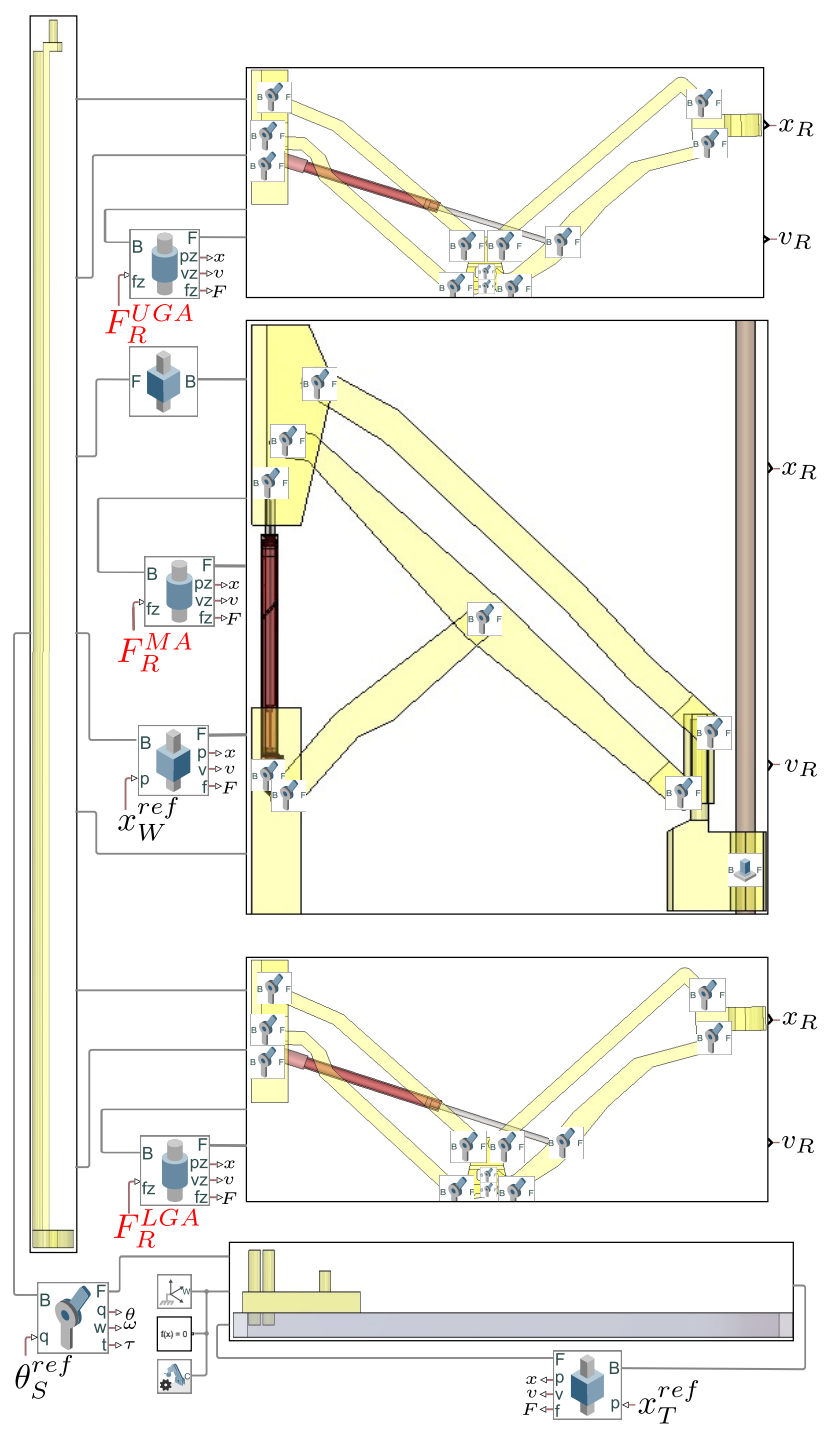

Figure 7: The MATLAB-Simulink@ MBS model.

\section{Benchmark System}

State-of-the-art hydraulically-actuated systems used in offshore drilling equipment and cranes are introduced and explained in the works of Bak (2014), Kjelland (2016), Sørensen (2016), and Hagen et al. (2017). This paper presents a synthesis of the hydraulic actuation system together with the numerical simulation models of the MA and the GAs reach motion.

The considered benchmark system is based on stateof-the-art hydraulic load-sensing valves (i.e., pressure compensated proportional directional control valves) including passive load-holding valves on both cylinder ports. The individual actuators are powered by a central HPU ensuring a constant supply pressure $\left(p_{S}^{i}\right)$ and a fixed return pressure $\left(p_{R}^{i}\right)$. Fig. 8 shows the layout of the benchmark system and the general architecture 
Table 2: Actuator requirements of the PRM.

\begin{tabular}{ll}
$\mathrm{R}-$ reach distance & $4.0[\mathrm{~m}]$ \\
$\mathrm{MA}-$ cylinder speed & $0.12\left[\frac{\mathrm{m}}{\mathrm{s}}\right]$ \\
$\mathrm{W}-$ max lifting capacity & $14[\mathrm{mT}]$ \\
$\mathrm{W}-$ hoisting speed & $1.0\left[\frac{\mathrm{m}}{\mathrm{s}}\right]$ \\
$\mathrm{W}-$ vertical travel distance & $25[\mathrm{~m}]$ \\
$\mathrm{T}-$ horizontal travel distance & $10[\mathrm{~m}]$ \\
$\mathrm{T}-$ travel speed & $0.5\left[\frac{\mathrm{m}}{\mathrm{s}}\right]$ \\
$\mathrm{S}-$ column rotate angle & $360[\mathrm{o}]$ \\
$\mathrm{S}-$ rotational speed & $5[\mathrm{rpm}]$ \\
\hline
\end{tabular}

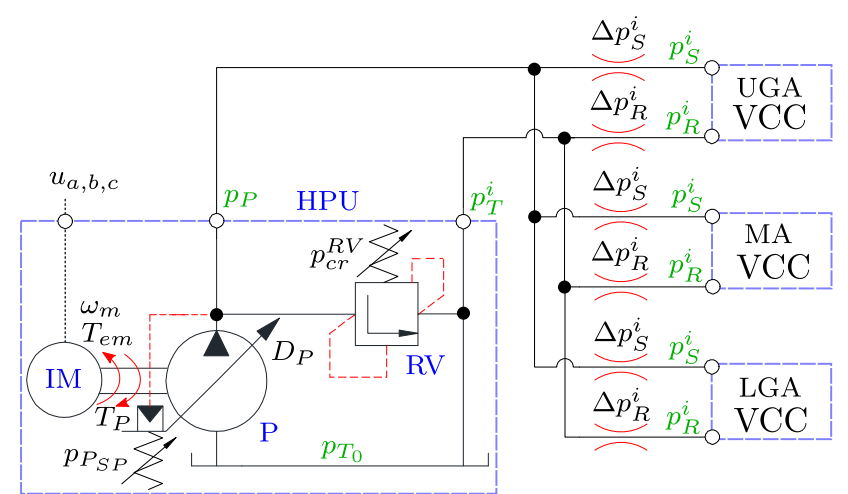

Figure 8: Benchmark system layout (simplified schematic).

of the VCC is shown in Fig. 10.

The HPU consists of an Induction Motor (IM) connected to the $50[\mathrm{~Hz}] \mathrm{AC}$ grid:

$$
\left[\begin{array}{l}
u_{a} \\
u_{b} \\
u_{c}
\end{array}\right]=\left[\begin{array}{c}
A_{\text {peak }} \sin \left(\omega_{F} t\right) \\
A_{\text {peak }} \sin \left(\omega_{F} t-2 / 3 \pi\right) \\
A_{\text {peak }} \sin \left(\omega_{F} t-4 / 3 \pi\right)
\end{array}\right]
$$

where

$$
A_{\text {peak }}=\frac{V_{L}}{\sqrt{3}} \sqrt{2}
$$

and $V_{L}=690[V]$ is the RMS voltage, rotating the hydraulic pump at a constant angular velocity $\left(\omega_{m}\right)$, a variable axial-piston Pump $(\mathrm{P})$ with max displacement $D_{P}$, a hydraulic tank with pressure $p_{T_{0}}$, and a pressure Relief-Valve (RV) $\left(p_{c r}^{R V}=210[b a r]\right)$ for safety purpose. The transmission lines between the HPU and the VCCs represent the supply and return flows. The equivalent pressure losses across the lines $\left(\Delta p_{S}^{i}\right.$ and $\left.\Delta p_{R}^{i}\right)$ are estimated in Section (3.3).

\subsection{Actuator Requirements}

From the inverse dynamic analysis, the minimum actuator requirements of the MA and GAs cylinders are identified. In addition to the minimal values from the considered drive cycle, the cylinders must deliver some extra force $( \pm 5[k N])$ to account for potential forces distributed from wind and additional centripetal accelerations. The requirements considered when sizing the VCCs are listed in Table 3.

Table 3: Actuator requirements.

\begin{tabular}{lll}
\hline Description & MA & GAs \\
\hline Displacement: & $1.70[\mathrm{~m}]$ & $1.04[\mathrm{~m}]$ \\
Velocity: & $\pm 0.12\left[\frac{m}{\mathrm{~s}}\right]$ & $\pm 0.106\left[\frac{\mathrm{m}}{\mathrm{s}}\right]$ \\
Extension force: & $62[\mathrm{kN}]$ & $15[\mathrm{kN}]$ \\
Retraction force: & $2.5[\mathrm{kN}]$ & $3[\mathrm{kN}]$ \\
\hline
\end{tabular}

The dominating design value when sizing the hydraulic cylinders is the buckling factor, and according to regulations (DNVGL-CG-0128), the accepted criterion for buckling in hydraulic cylinders is to use a safety factor $f_{s}=4$, unless a more accurate analysis of the buckling load is carried out. The minimum rod diameter is determined by:

$$
D_{r}^{i} \geq \sqrt[4]{\frac{64 f_{s} L_{C_{t o t}}^{i 2} F_{C_{\max }}^{i}}{\pi^{3} E}}
$$

where $L_{C_{t o t}}^{i}$ is the total length of the cylinder in extended position, $F_{C_{\max }}^{i}$ is the maximum force acting on the cylinder (Table 3), and $E$ is the elasticity modulus $(206[G P a])$. The piston diameter may be selected based on:

$$
D_{p}^{i} \geq \sqrt{\frac{4}{\pi} \frac{F_{C_{\max }}^{i}}{p_{A}-p_{B} \varphi^{i}}}
$$

where $p_{A}$ is the piston side pressure typically set to $20 \ldots 30[$ bar $]$ below the maximum pump pressure $\left(p_{P}=\right.$ $210[$ bar $]), p_{B}$ is the rod side pressure, and $\varphi^{i}$ the ratio between rod and piston area.

Based on eq. (11-12) assuming $f_{s}=2.7[-], p_{A}=$ $180[\mathrm{bar}]$, and $p_{B}=5[\mathrm{bar}]$, the dimensions in Table 4 are chosen for the MA and GAs cylinders according to the ISO 6022 standard.

Table 4: Selected cylinder dimensions and max induced load pressures.

\begin{tabular}{lll}
\hline Description & MA & GAs \\
\hline Rod diameter: & $70[\mathrm{~mm}]$ & $40[\mathrm{~mm}]$ \\
Piston diameter: & $100[\mathrm{~mm}]$ & $63[\mathrm{~mm}]$ \\
Max load pressure: & $81.5[\mathrm{bar}]$ & $51.1[\mathrm{bar}]$ \\
\hline
\end{tabular}




\subsection{Hydraulic Power Unit}

The HPU's pump is sized based on the required flow of the MA and GAs cylinders:

$$
Q_{\text {max }}^{i}= \begin{cases}v_{C}^{i} A_{A}^{i}, & v_{C}^{i} \geq 0 \\ v_{C}^{i} A_{B}^{i}, & v_{C}^{i}<0\end{cases}
$$

during the considered motion cycle and the required pump pressure $p_{P_{S P}}=p_{\text {Lmax }}+\Delta p_{\text {Smax }}+30[$ bar $]$, where $p_{\text {Lmax }}=81.5[\mathrm{bar}]$ is the highest load induced pressure in the inlet chamber of the cylinders (Table 4) and $\Delta p_{S \max }$ is the highest pressure loss between the HPU and the VCCs. The total flow demand for the pump $\left(Q_{P \max }=\left(Q_{M A}+2 \cdot Q_{G A}\right)_{\max }\right)$ is approximately $84.6\left[\frac{l}{\min }\right]$ when using the velocity values in Table 3. The maximum flows for each actuator are $Q_{\max }^{M A} \approx 57\left[\frac{l}{\min }\right]$ and $Q_{\max }^{G A} \approx 20\left[\frac{l}{\min }\right]$.

The effective pump losses are evaluated using the flow losses $\left(Q_{S}\right)$ and torque losses $\left(T_{S}\right)$ measured from steady-state experimental data in Williamson and Ivantysynova (2007) using a reference unit equivalent to the considered pump. The losses are scaled to the desired pump displacement according to:

$$
\begin{aligned}
Q_{S} & =\lambda^{2} \cdot Q_{S}^{r e f} \\
T_{S} & =\lambda^{3} \cdot T_{S}^{r e f} \\
\lambda & =\sqrt[3]{\frac{D_{P}}{D_{P}^{r e f}}}
\end{aligned}
$$

where the quantities of the reference unit is denoted by the subscript ref and $\lambda$ is a scaling factor as a function of the displacement of the considered pump $\left(D_{P}\right)$ and the reference unit $\left(D_{P}^{r e f}\right)$.

Selecting a $690[\mathrm{~V}], 50[\mathrm{~Hz}], 3$-phase IM with 4 poles gives in general a rotational speed of $n_{m}=$ 1450...1500 [rpm], depending on the external load.

From:

$$
D_{P}>\frac{Q_{\max }}{n_{m}}
$$

the required pump displacement must be greater than $54.7\left[\frac{\mathrm{cm}^{2}}{\mathrm{rev}}\right]$ (assuming $n_{m}=1450[\mathrm{rpm}]$ ), and according to:

$$
T_{P}>\frac{p_{P} D_{P}}{2 \pi}
$$

the available torque from the IM must be greater than $T_{P}=104.4[N m]$.

Considering the maximum pump pressure $p_{P}=$ $210[\mathrm{bar}]$, a displacement $D_{P}=60\left[\frac{\mathrm{cm}^{3}}{\mathrm{rev}}\right]$ and rotational speed $n_{m}=1500[\mathrm{rpm}]$, the volumetric (leakage) loss $\left(Q_{S}=4.3\left[\frac{l}{\min }\right]\right)$ and the hydro-mechanical (friction) loss $\left(T_{S}=20.81[\mathrm{Nm}]\right)$ are estimated based on the scaled measurements. Hence, when accounting for the estimated leakages in the pump, a variable displacement pump with $D_{P}=60\left[\frac{\mathrm{cm}^{3}}{\mathrm{rev}}\right]$ is sufficient. Finally, an electric motor can be selected based on the estimated maximum power $\left(\dot{E}_{I M}^{M e c h}=\omega_{m}\left(T_{P}+T_{S}\right)\right)$ of $21.05[k W]$ that the IM must deliver continuously.

\subsection{Hydraulic Transmission Lines}

Between the HPU and the VCCs, the hydraulic flow in the transmission lines is restricted through flexible drag chains between the moving elements of the PRM, i.e., between the upper beam and the upper trolley, between the upper trolley and the column, and between the column and the VCC of the individual arms. Also, in the supply line, a filter and a shut-off valve are included, as illustrated in Fig. 9.

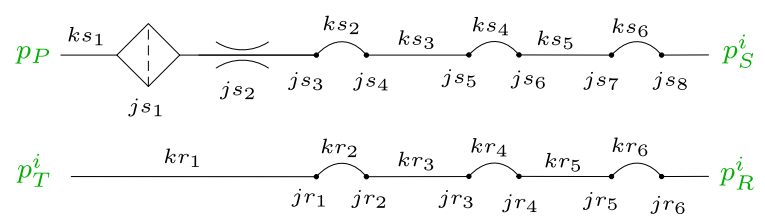

Figure 9: Considered supply and return line loss elements.

Equations for turbulent flow are used according to Stecki and Garbacik (2002). The losses are the pressure drop $\left(\Delta p_{L}^{i}\right)$ in the supply line $\left(p_{P}-p_{S}^{i}\right)$ and in the return line $\left(p_{R}^{i}-p_{T}^{i}\right)$. In detail, line losses occur due to the large ratio between length and diameter of the lines and hoses, and all local losses, i.e., disturbances in the shut-off valve, inlet-filter and changes in flow area between lines, hoses, and fittings. For the hoses in each drag-chains, a $90^{\circ}$ bend accounts for the local loss coefficients. The total flow loss may be estimated by:

$$
\Delta p_{L}^{i}=(\underbrace{\sum \lambda_{k i} \frac{l_{k i}}{d_{k i} A_{k i}^{2}}}_{K_{k i}(\text { line })}+\underbrace{\sum \xi_{j i} \frac{1}{A_{j i}^{2}}}_{K_{j i} \text { (local) }}) \frac{\rho}{2} Q_{L}^{2 i}
$$

where the subscript $i$ denotes the actuator, $L$ the transmission line type (supply or return), $k$ the line or hose number, and $j$ the local loss element number according to Fig. 9. In eq. (20) the coefficient of line pressure losses $\left(\lambda_{k i}\right)$, assuming heat transfer between the fluid and the environment, is defined. Depending on the Reynold's Number in eq. (21), $\xi_{j i}$ is the coefficient of local losses obtained from Stecki and Garbacik (2002), $l_{k i}$ is the length of the line, $d_{k i}$ is the diameter of the line, $A_{k i}$ and $A_{j i}$ is the effective flow area, and $\rho=860\left[\frac{\mathrm{kg}}{\mathrm{m}^{3}}\right]$ 
is the density of the hydraulic fluid.

$$
\begin{aligned}
\lambda_{k i} & =\frac{75}{R e_{k i}} \\
R e_{k i} & =\frac{v_{k i} d_{k i}}{\nu}
\end{aligned}
$$

$v_{k i}$ is the average flow velocity $\left(v_{k i}=Q_{a v g} / A_{k i}\right)$, and $\nu=46 \cdot 10^{-6}\left[\frac{m^{2}}{\mathrm{~s}}\right]$ is the kinematic viscosity of the fluid.

The flow loss coefficients are combined as the gain $K_{L, i}$, and eq. (19) may be rewritten as:

$$
\Delta p_{L}^{i}=K_{L}^{i} \frac{\rho}{2} Q_{L}^{2 i}
$$

where the estimated gains are listed Table 5 .

Table 5: Transmission line loss gains.

\begin{tabular}{llll}
\hline Gain & UGA & MA & LGA \\
\hline$K_{S}^{i}[-]:$ & $9.97 \cdot 10^{8}$ & $1.52 \cdot 10^{9}$ & $1.31 \cdot 10^{9}$ \\
$K_{R}^{i}[-]:$ & $4.92 \cdot 10^{8}$ & $7.81 \cdot 10^{8}$ & $8.10 \cdot 10^{8}$ \\
\hline
\end{tabular}

Finally, the effective back pressure from the HPU's $\operatorname{tank}\left(p_{T}^{i}\right)$ is estimated:

$$
p_{T}^{i}=p_{T_{0}}+\rho g h^{i}
$$

where $p_{T_{0}}$ is the local tank pressure, $g$ is the gravitational acceleration, and $h^{i}$ is the height between the machine interface located on the upper beam and the $i^{\text {th }}$ VCC.

\subsection{Control Valves}

Pressure compensated Proportional Directional Control Valves (PDCVs) are popular in the offshore industry since the flow characteristics are load independent, and disturbance from other actuators connected to the same transmission line is avoided. A PVG32 from SauerDanfoss is selected according to the flow required by the actuators. From the available sizes, PDCVs with a flow capacity of $100\left[\frac{l}{\mathrm{~min}}\right]$ and $40\left[\frac{l}{\mathrm{~min}}\right]$ are selected for the MA and GAs, respectively.

\subsection{Load-Holding Valves}

The size of the Counter-Balance Valves (CBVs) is chosen to match the rated flow of the PDCVs. CBVs with a flow capacity of $120\left[\frac{l}{\mathrm{~min}}\right]$ for the MA and $60\left[\frac{l}{\mathrm{~min}}\right]$ for the GAs are selected from SUNhydraulics. The Check Valve $(\mathrm{CV})$ cracking pressures is $p_{c r C}^{C V}=1.7$ [bar] for all CBVs.

To avoid unintended opening of the CBVs, it is recommended (Bak and Hansen, 2013) to set the cracking pressure of the Poppet Valve (PV) to a factor of 1.3 above the maximum load induced pressure $\left(p_{\text {Lmax }}\right)$ :

$$
p_{c r, i}^{P V} \geq 1.3 \cdot p_{L \max }
$$

The cracking pressures of the MA and GAs PVs are set, based on the maximum load pressures identified in Table 4, to 105.5 [bar] and 66.5 [bar], respectively.

The combination of PDCV and CBVs tends to induce oscillatory behavior or even instability (Sørensen, 2016; Hagen et al., 2019). Hence, the most critical design consideration when selecting the CBV is to choose the best pilot area ratio $\left(\alpha_{p}\right)$ for the considered system. Based on experience on similar applications, a pilot ratio $\alpha_{p}=3[-]$ is often chosen as a compromise between stability and energy efficiency.

\subsection{System Modeling}

A $22[k W]$ double squirrel cage IM from ABB is selected, and modeled according to Krause et al. (2002).

The VCC circuit for the MA and GAs are modeled based on Hagen et al. (2019) where a similar hydraulic system is validated on a single-boom crane. The equations used in the numerical model of the benchmark system are listed in Section (A.1). The force balance of the piston in eq. (41), that are interfacing with the MBS, is considered as well as the well-known pressure build-up equation that is applied several times to evaluate the system pressures elucidated in Fig. 10.

The following equations are used to simulate the power of the different elements of the benchmark system considered in the Sankey diagram in Fig. 26: electrical power from the $\mathrm{AC}$ grid;

$$
\dot{E}_{I n}^{E l}=u_{a} i_{a}+u_{b} i_{b}+u_{c} i_{c}
$$

mechanical power of the motor's shaft;

$$
\dot{E}_{I M}^{M e c h}=T_{e m} \omega_{m}
$$

hydraulic power of the pump;

$$
\dot{E}_{P}^{H y d}=Q_{P} \Delta_{p_{P}} .
$$

hydraulic power delivered to the individual VCCs;

$$
\dot{E}_{L}^{H y d}=Q_{L} p_{L}
$$

hydraulic power delivered by the PDCVs;

$$
\dot{E}_{V}^{H y d}=Q_{V_{I n}} p_{L S}
$$

hydraulic power in the cylinder;

$$
\dot{E}_{C}^{H y d}=F_{C} v_{C}
$$

and, finally, the mechanical power delivered by the arms;

$$
\dot{E}_{\text {Out }}^{M e c h}=F_{R} v_{C}
$$




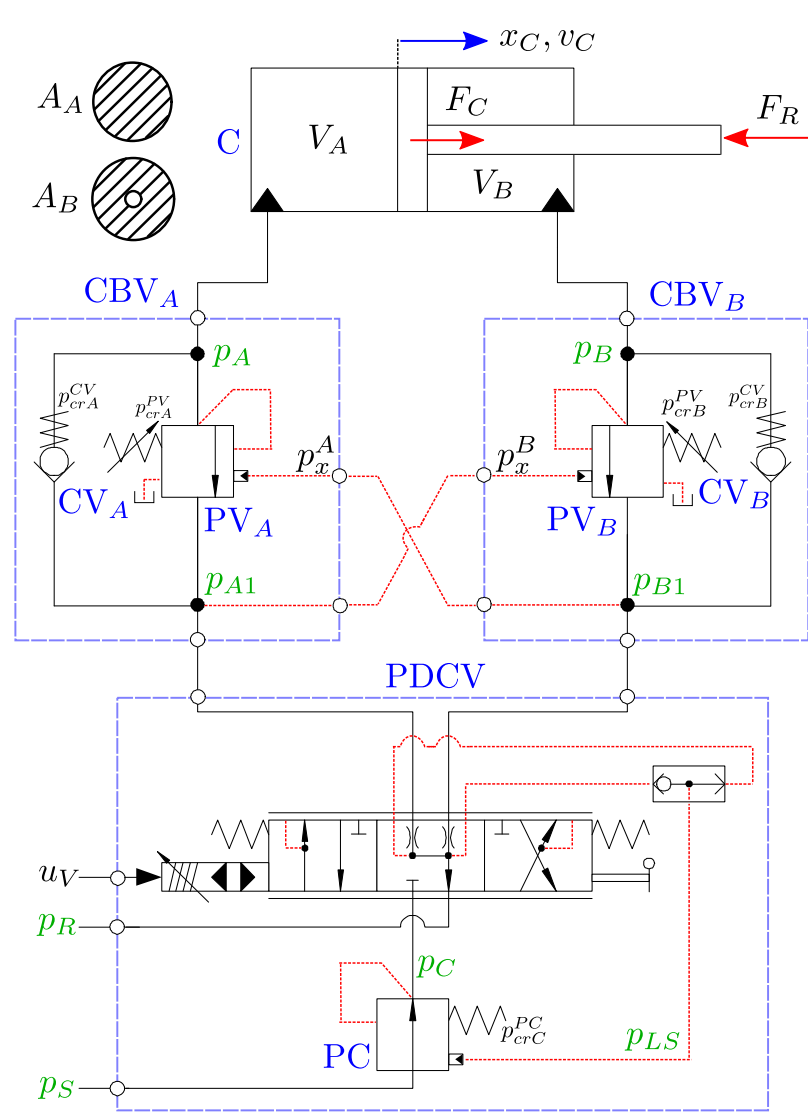

Figure 10: Valve-controlled cylinder architecture.

\section{Self-Contained System}

The self-contained electro-hydraulic cylinder drive concept investigated in Hagen et al. (2018) and successfully implemented and tested in Padovani et al. (2019) is scaled to the MA and GAs cylinders dimensions selected for the benchmark system. The combination of a Servo-Motor (SM) and a fixed-displacement hydraulic machine $(\mathrm{P})$ drives the cylinder arranged in a closedcircuit configuration, as illustrated in Fig. 11.

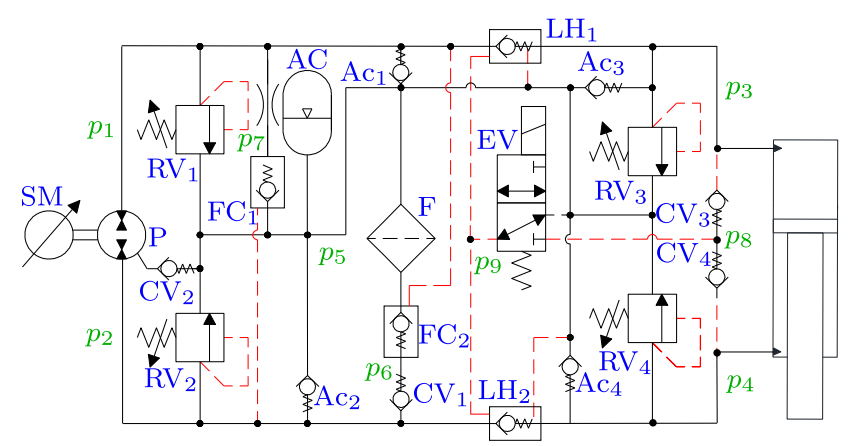

Figure 11: Self-contained cylinder architecture.

The differential flow dictated by the cylinder's unequal areas is balanced by two pilot-operated check valves $\left(\mathrm{FC}_{1-2}\right)$, by the Anti-cavitation valves $\left(\mathrm{Ac}_{1-2}\right)$ and the Check Valve $\mathrm{CV}_{1}$. The bladder accumulator (AC) represents the sealed reservoir of the SCC. The Pilot-Operated Check Valves (POCV) $\mathrm{LH}_{1}$ and $\mathrm{LH}_{2}$ are used for passive load-holding purposes by isolating the cylinder when the $3 / 2$ electro-valve (EV) is not actuated. To enable motion, the $\mathrm{EV}$ is actuated resulting in transferring the highest cylinder pressure, selected through the $\mathrm{CV}_{3}$ and $\mathrm{CV}_{4}$, into the opening pilot line of $\mathrm{LH}_{1}$ and $\mathrm{LH}_{2}$. Pressure Relief Valves $\left(\mathrm{RV}_{1-4}\right)$ are installed on both pump ports and on both cylinder ports to avoid over-pressurizations. Ac valves $\left(\mathrm{Ac}_{3-4}\right)$ are also connected to the cylinder chambers. Finally, the low pressure filter $(\mathrm{F})$ is comprised in the system.

To benefit from the energy recovery capability of the $\mathrm{SCC}$, this paper proposes the system layout as shown in Fig. 12 to drive the MA and GAs of the considered PRM.

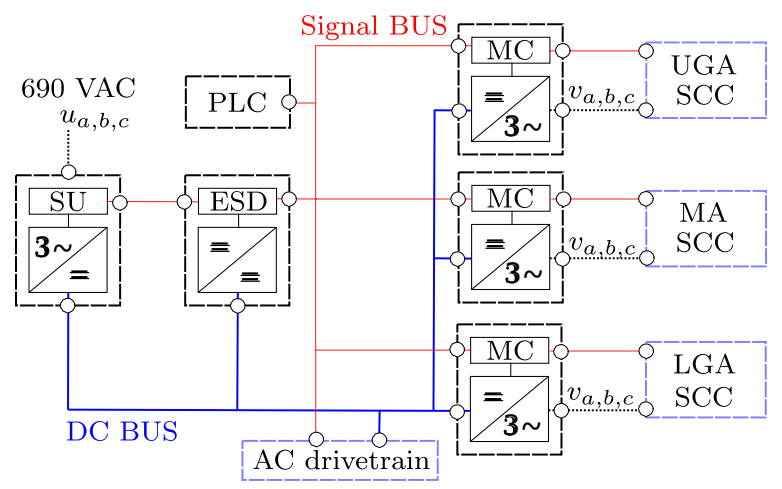

Figure 12: Proposed electric power distribution layout when using self-contained cylinders together with existing AC drivetrains (simplified schematic).

The Supply Unit (SU) converts the AC voltage from the electric grid to a DC bus voltage that is shared with the individual DC to AC PWM inverters controlled by a Motion Controller (MC). The MC includes a cascaded controller that takes care of cylinder position, pressure-feedback, and the servo-motor's speed through a space vector PWM controller (field oriented control). For additional energy storage (i.e., when the winch is lowering, the travel or slew motors are braking) and for emergency operation, in case of power shut down, a Electrochemical Storage Device (ESD) (i.e., a battery) is connected to the DC bus through a DC/DC converter. An industrial Programmable Logic Controller (PLC) is used, in combination with emergency stop modules, for safety functionalities, motion trajectory generators, and is communicating with the SCC's I/Os and the MCs, SU, and ESD, using a standard bus communication protocol (e.g, Profinet, Profibus, Sercos, etc.). 


\subsection{Sizing of Components}

Equivalent components to the ones used in the reference concept (Padovani et al., 2019) are scaled according to the flow and pressure (power) requirements used when sizing the benchmark system. The selected SMs are suitable for potentially explosive environments.

Table 6: Selected components for the SCCs.

\begin{tabular}{|c|c|c|c|}
\hline & Description & MA & GAs \\
\hline SM: & $\mathrm{E}$ & 18B-024 & 098 \\
\hline P: & exroth A10FZG & $18\left[\mathrm{~cm}^{3}\right]$ & $6\left[\mathrm{~cm}^{3}\right]$ \\
\hline $\mathrm{F}:$ & Rexroth 10 TEN & $95\left[\frac{l}{\min }\right]$ & $62\left[\frac{l}{\min }\right.$ \\
\hline $\mathrm{AC}:$ & Rexroth HAB-CE & $20[l]$ & $10[l]$ \\
\hline EV: & Argo-H. SD1E-A3 & $30\left[\frac{l}{\min }\right]$ & $30\left[\frac{l}{\min }\right.$ \\
\hline LH: & SUN CVEV XFN & $120\left[\frac{l}{\min }\right.$ & $60\left[\frac{l}{\min }\right]$ \\
\hline FC: & SUN CKEB XCN & $120\left[\frac{l}{\min }\right.$ & $60\left[\frac{l}{\min }\right]$ \\
\hline $\mathrm{CV}_{1}$ : & Hawe RB2 & $50\left[\frac{l}{\min }\right]$ & $50\left[\frac{l}{\min }\right.$ \\
\hline $\mathrm{CV}_{2}$ : & Hawe RK4 & $120\left[\frac{l}{\min }\right.$ & $120\left[\frac{l}{\min }\right]$ \\
\hline $\mathrm{CV}_{3-4}:$ & Hawe RK2 & $50\left[\frac{l}{\min }\right]$ & $50\left[\frac{l}{\min }\right]$ \\
\hline $\mathrm{Ac}_{1-2}$ : & Hawe RK4 & $120\left[\frac{l}{\min }\right.$ & $120\left[\frac{l}{\min }\right]$ \\
\hline $\mathrm{Ac}_{3-4}:$ & Hawe RB2 & $50\left[\frac{l}{\min }\right]$ & $50\left[\frac{l}{\min }\right]$ \\
\hline $\mathrm{RV}_{1-4}$ & SUN RD & $95\left[\frac{l}{\min }\right]$ & $45\left[\frac{l}{\min }\right]$ \\
\hline
\end{tabular}

\subsection{System Modeling}

The servo-motor, a surface mounted permanent magnet synchronous motor, and the variable speed driver, using field-oriented control (vector control), is modeled based on the work of Harnefors (2003). The hydraulic circuit for the MA and GAs SCCs, are modeled based on Padovani et al. (2019) where a similar system is modeled and validated on a single-boom crane. The equations used in the numerical model of the SCCs are listed in Section (A.2). The force balance of the piston in eq. (60), that are interfacing with the MBS, is considered as well as the well-known pressure build-up equation that is applied several times to evaluate the system pressures elucidated in Fig. 11.

\section{Simulation Results}

First, an inverse dynamic analysis is carried out for design purpose and the driving cycles (i.e., the motion and load cycle) for the desired operational sequence (reach, winch, slew and trolley motion) are formulated. The MA and GAs kinematics are thereafter validated, and the output power that each actuator must deliver is estimated, together with an analysis of the mechanical energy of the arms that have potential to be regenerated when using SCCs. Secondly, the motion performance, power consumption, and efficiency of the benchmark system and the self-contained system are presented, and finally, the energy consumptions of both systems are compared.

\subsection{Inverse Dynamic Analysis}

\subsubsection{Actuator Force}

It was found that the scissor mechanism of the MA tends to have high gearing ratio in the inner position $\left(x_{C}^{M A}=1.5-1.7[m]\right)$, causing high peaks in the reaction force when accelerating or decelerating. Fig. 13 demonstrates the actuator force for maximum load and with the considered operational load, i.e., a quadruple stand of $5 \frac{7}{8}[$ Inch $](149.3[\mathrm{~mm}]$ in diameter $)$ drill-pipes.

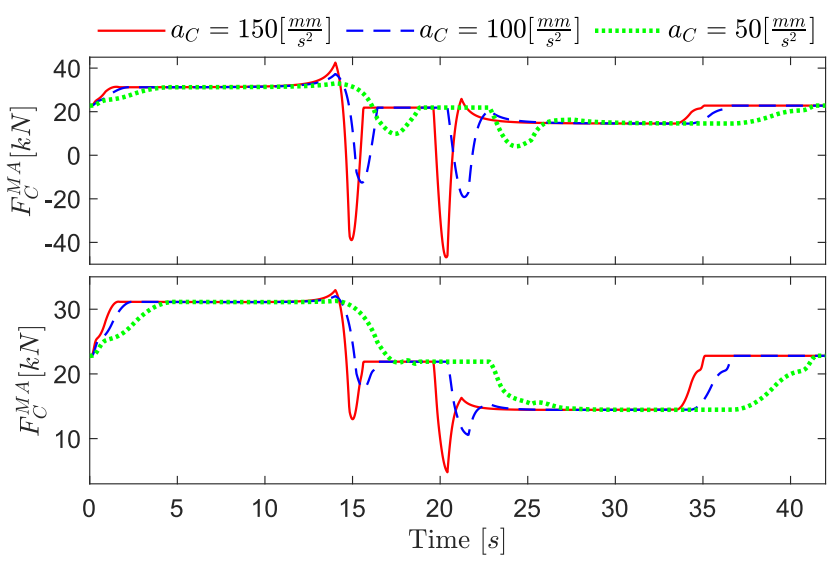

Figure 13: MA cylinder force at different acceleration profiles: (top) with max payload (14 $[m T]$ ); (bottom) with normal operational payload $(1.5[m T])$.

To reduce the force peak, the acceleration set-point $\left(a_{C_{S P}}=50\left[\frac{m m}{s^{2}}\right]\right.$, green line in Fig. 13) is chosen as low as possible for the given stroke length and velocity.

\subsubsection{Considered Motion Cycles}

The generated motion trajectories for the MA cylinder and the GAs cylinders for the considered operation sequence are plotted in Fig. 14. The generated motion trajectories for the reach arms, winch actuator $\left(x_{W}[m]\right.$ and $\left.v_{W}\left[\frac{m}{s}\right]\right)$, trolley actuator $\left(x_{T}[m]\right.$ and $\left.v_{T}\left[\frac{m}{s}\right]\right)$, and the slew actuator $\left(\theta_{S}[\mathrm{rad}]\right.$ and $\left.\omega_{S}\left[\frac{\mathrm{rad}}{\mathrm{s}}\right]\right)$ are plotted in Fig 15.

\subsubsection{Load Cycles}

The resulting actuator load cycles from the inverse dynamics are demonstrated in Fig. 16 for the reach arms cylinders, and in Fig. 17 for the winch, trolley and slew actuators. From Fig. 16, it can be seen that the highest force in the MA cylinder is when the PRM is slewing 


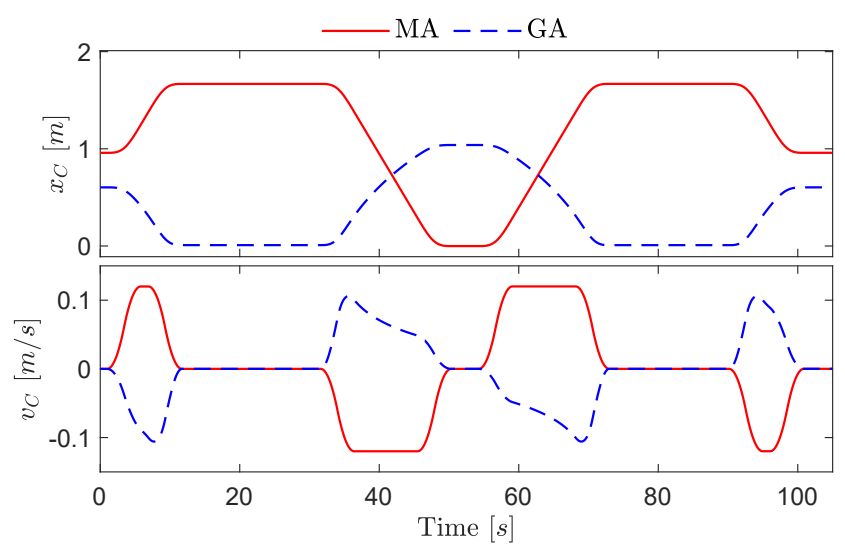

Figure 14: MA and GAs motion reference: (top) position; (bottom) velocity.

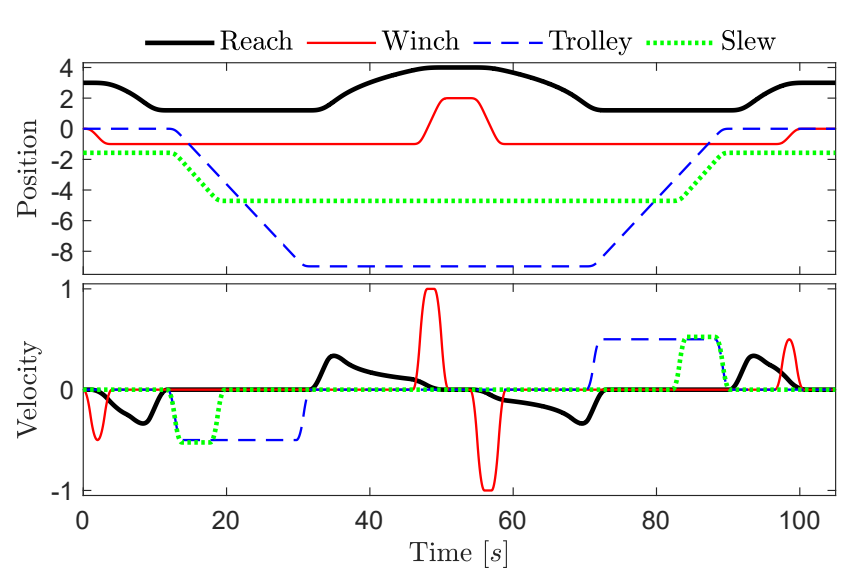

Figure 15: Generated motion trajectories: (top) position reference $x_{R}[m], x_{W}[m], x_{T}[m]$, and $\theta_{S}[\mathrm{rad}]$; (bottom) velocity reference $v_{R}\left[\frac{m}{s}\right], v_{W}\left[\frac{m}{s}\right]$, $v_{T}\left[\frac{\mathrm{m}}{\mathrm{s}}\right]$, and $\omega_{S}\left[\frac{\mathrm{rad}}{\mathrm{s}}\right]$.

with maximum load. This is because of the resulting centripetal force from the moving drill-stand.

\subsubsection{Energy Saving Potential}

The simulated actuators output power in Figs. 1819 gives an indication of the energy recovery potential during the considered operational sequence. When the output power has a negative sign then the actuator is exposed to overrunning load (i.e., velocity and force/torque have the same direction) and the SCC have the potential to recover energy.

From Fig. 20 it is demonstrated that the energy consumed to actuate the PRM during the considered motion sequence is $888[k J]$ without energy recovery, and $644[k J]$ if considering $100 \%$ efficient regeneration. Hence, the potential energy that can be regenerated is $244[k J](27.5 \%)$.

Based on the considered operational sequence, Table 7 displays at which steps the actuators are in use

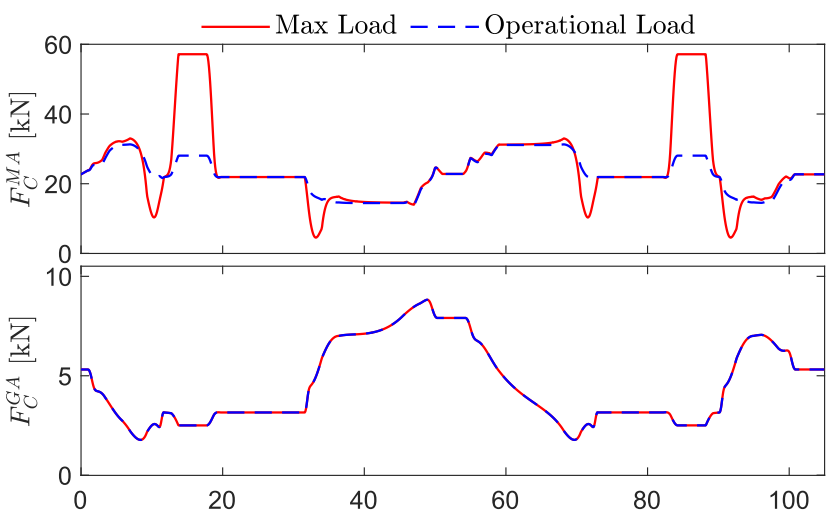

Figure 16: Actuator load cycle at max load and operational load: (top) main arm; (bottom) guide arms.

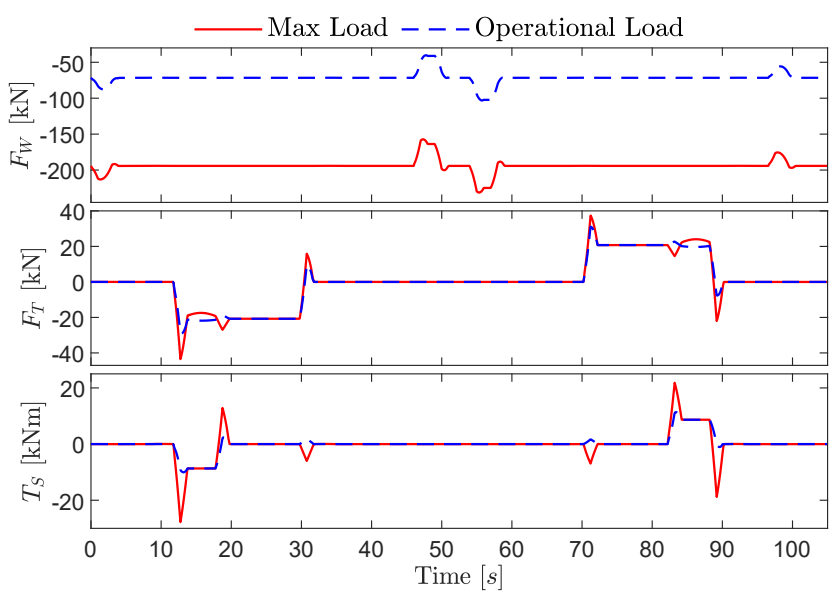

Figure 17: Actuator load cycle at max load and operational load: (top) winch; (middle) trolley; (bottom) slew.

or not during the different cycle steps and specifies if an actuator can potentially regenerate energy (overrunning load), highlighted using green letters or consuming energy (resistant load), highlighted in red.

Table 7: Actuation overview.

\begin{tabular}{lllllllll}
\hline Step: & $0-1$ & $1-2$ & $2-3$ & $3-4$ & $4-3$ & $3-2$ & $2-1$ & $1-0$ \\
\hline $\mathrm{R}_{M A}:$ & on & off & off & $\underline{\text { on }}$ & on & off & off & on \\
$\mathrm{R}_{G A s}:$ & on & off & off & on & $\underline{\text { on }}$ & off & off & on \\
$\mathrm{W}:$ & on & off & off & on & on & off & off & on \\
$\mathrm{T}:$ & off & on & on & off & off & on & on & off \\
$\mathrm{S}:$ & off & on & off & off & off & off & on & off \\
\hline
\end{tabular}

From the presented inverse dynamic analysis, it is clear that the actuators that can potentially regenerate energy are the MA, the GAs, and the winch. Additionally, when the trolley and slew actuators are braking (decelerating), there is a short period when the actuators can regenerate energy. Furthermore, when the MA 


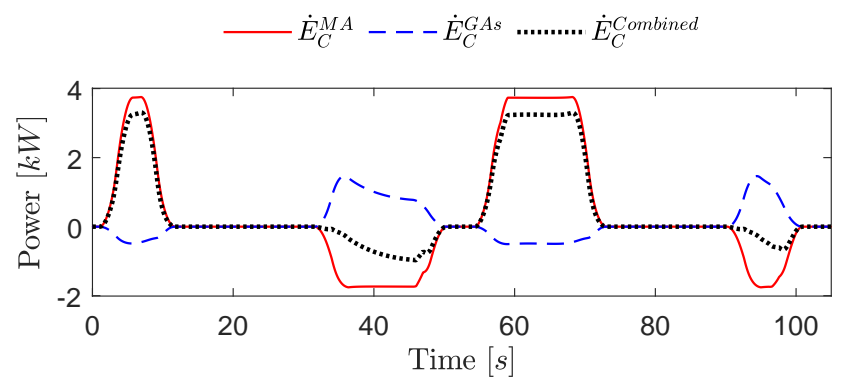

Figure 18: Main arm and guide arms; actuator output power.

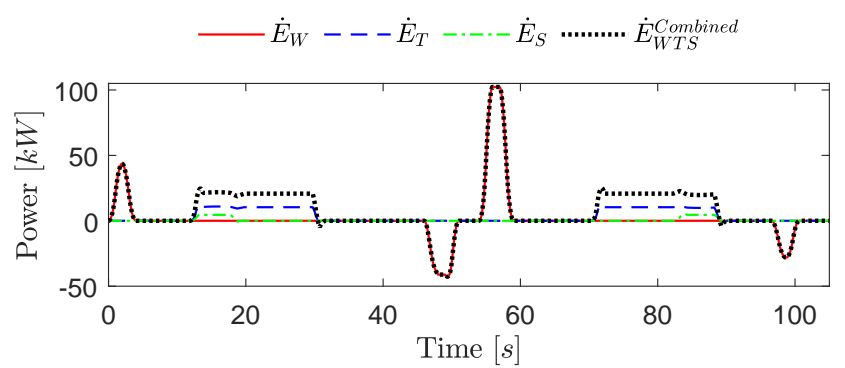

Figure 19: Winch, trolley and slew; actuator output power.

regenerates energy the GAs consume energy and vice versa. Hence, by introducing self-contained electrohydraulic cylinders connected to a common DC bus (Fig. 12) there is potential to directly supply electrical power to the GAs when the MA is regenerating, and when the GAs is regenerating, the demanded power from the grid to actuate the MA may be reduced.

When considering the reach motion separately, it can be seen from Fig. 21, that by sharing the energy between the MA and the GAs, the energy consumption of the reach motion, potentially, can be reduced with almost $50 \%$.

Furthermore, using an external storage device, i.e., a battery pack, the regenerated energy from the winch during other operations not detailed in this study and the remaining energy from the MA can be stored and reused, resulting in further energy savings.

\subsection{Benchmark System}

The numerical model of the induction motor and of the hydraulic system (Appendix (A.1)) representing the benchmark system is simulated according to the motion reference of the considered operational cycle (Figs. 14-15) evaluated in the inverse dynamic analysis. The performance of the different subsystems (i.e, the hydraulic power unit, the transmission lines, the main arm VCC, and the two guide arms VCCs) are demonstrated.

In Fig. 22, the effective magnitudes of the HPU when idling (i.e., when no motion is demanded) is for the

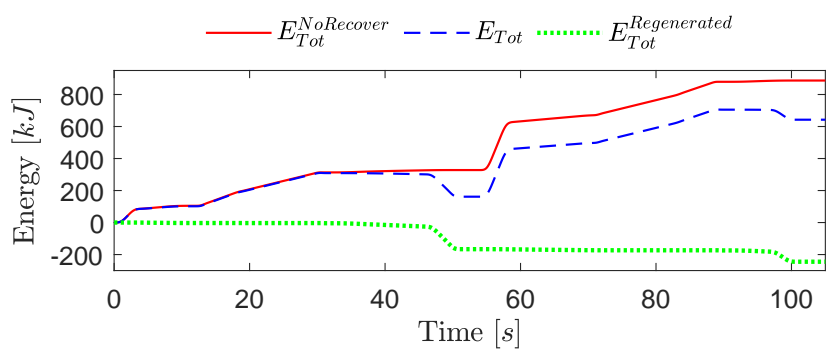

Figure 20: The total energy consumption of all actuators.

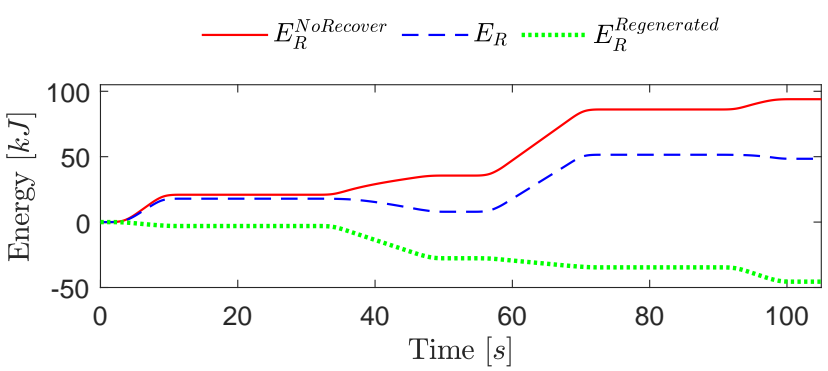

Figure 21: Energy consumption of the reach arm actuators.

pump pressure $p_{P}=125[\mathrm{bar}]$, pump displacement $D_{P}=1.9\left[\frac{\mathrm{cm}}{\mathrm{rev}}\right]$, pump flow $Q_{P}=0\left[\frac{l}{\mathrm{~min}}\right]$, and pump torque $T_{P}=19.7[\mathrm{Nm}]$.

When maximum velocity is demanded, the pump displacment increases up to about $D_{P}=56\left[\frac{\mathrm{cm}^{3}}{\mathrm{rev}}\right]$ resulting in an output flow of $Q_{P}=80\left[\frac{l}{\mathrm{~min}}\right]$ and in a required torque of $T_{P}=125.4[\mathrm{Nm}]$.
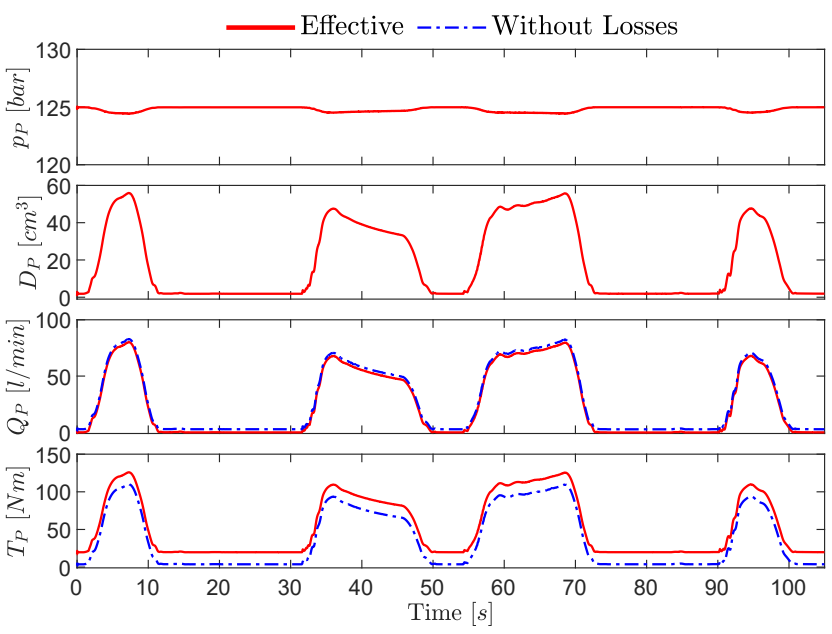

Figure 22: Hydraulic power unit performance.

In Fig. 23, the highest pressure drop of the supply and return lines are for the main arm $\Delta p_{S}^{M A}=$ $12.6[$ bar $]$ and $\Delta p_{R}^{M A}=5.9[$ bar] , the upper guide arm $\Delta p_{S}^{U G A}=8.0[b a r]$ and $\Delta p_{R}^{U G A}=3.7[b a r]$, and the lower guide arm $\Delta p_{S}^{L G A}=10.3[$ bar] and $\Delta p_{R}^{L G A}=6.0[\mathrm{bar}]$.

From Fig. 24, the highest error of the reach position 


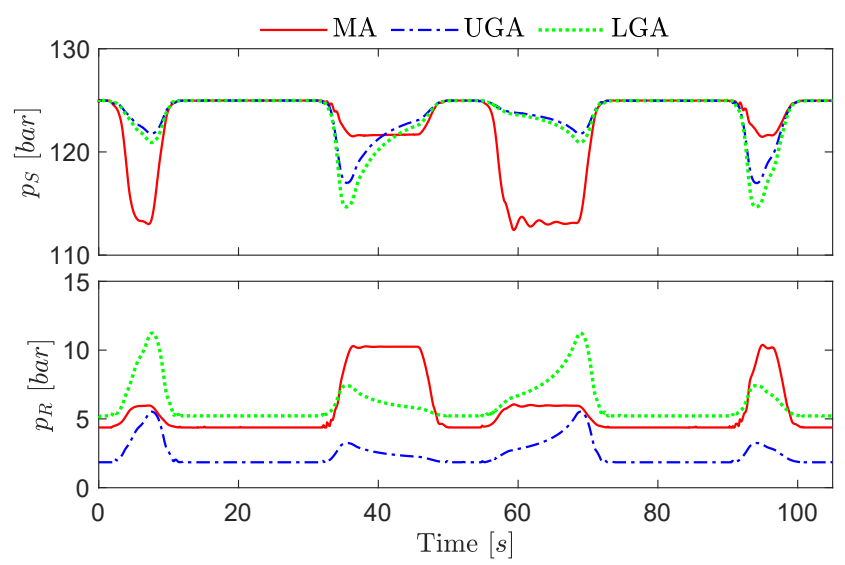

Figure 23: Transmission line pressures.

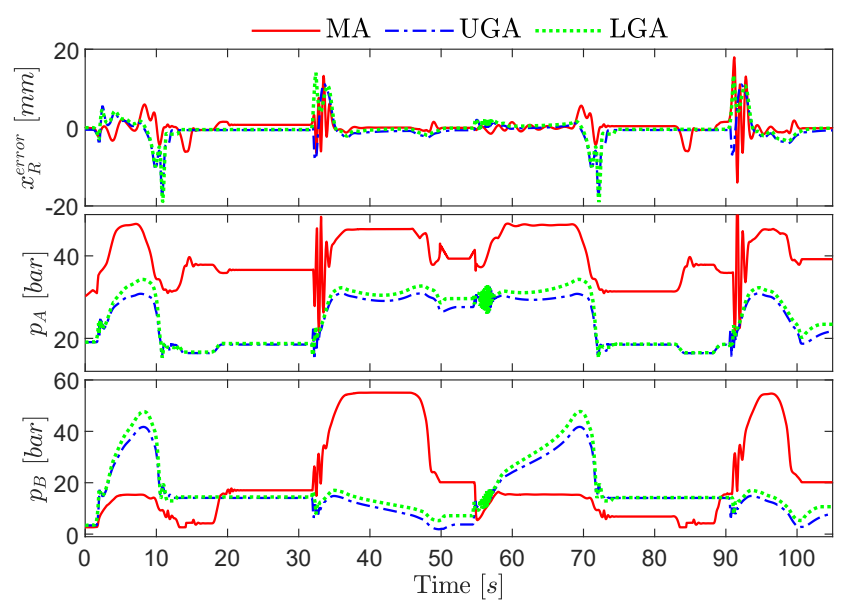

Figure 24: Reach arms performance.

is $14[\mathrm{~mm}]$ for the main arm, $17.5[\mathrm{~mm}]$ for the upper guide arm, and $19[\mathrm{~mm}]$ for the lower guide arm. The resulting accuracy is acceptable since the drillstand can move freely within a tolerance of $50[\mathrm{~mm}]$ when guided during the reach motion. The pressures in the cylinders behave as expected, and there are limited fluctuations when the cylinder starts to move.

The power consumption of the different elements of the benchmark subsystems are highlighted in Fig. 25.

The dominating losses of the benchmark system are illustrated in Fig. 26 and consist of the following terms:

- Induction motor - electric and mechanical losses (copper, Eddy current, hysteresis and viscous friction)

- Hydraulic pump - volumetric losses (leakage) eq. (14) and hydro-mechanical losses (friction) eq. (15)

- Transmission lines - hydraulic friction losses (pressure drop) eq. (19)

- Control valves - throttling losses eq. (53)

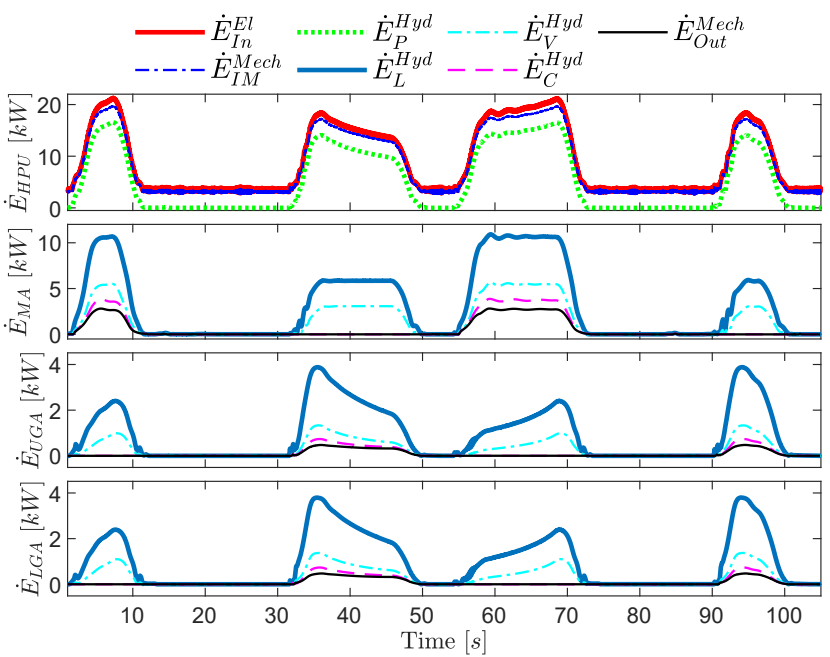

Figure 25: Power consumption of hydraulic power unit, main arm, upper guide arm, and lower guide arm.

- Load-holding valves - throttling losses eq. (53)

- Cylinder and arm mechanism - combined friction losses of the cylinders and the mechanical system eq. (8).

The average hydraulic efficiency when considering the VCCs separately, using the power from the supply line as input, is $21.6 \%$ for the main arm and $11.5 \%$ for the guide arms.

\subsection{Self-Contained System}

The numerical model of the self-contained system (Appendix (A.2)), includes the electro-hydraulic model of the main arm's SCC and two identical SCCs for the two guide arms.

The effective magnitudes of the SCC's motor-pump unit when idling are for the pump supply pressures $p_{1}^{M A}=0.23[$ bar $]$ and $p_{1}^{G A}=0.51$ [bar] (Fig. 27), the suction pressure $p_{2}^{M A}=0.25[$ bar $]$ and $p_{2}^{G A}=0.53[$ bar $]$ (Fig. 28). From Fig. 29, the rotational speed of the SMs is $0[\mathrm{rpm}]$, the supply flow is $0\left[\frac{l}{\mathrm{~min}}\right]$, and the torque of the pumps are $0[N \mathrm{~N}]$. It is shown that the SCCs do not demand any power when not moving, compared to the benchmark system where the HPU is constantly supplying flow to maintain the desired pressure level. The system pressures behave as expected when the SCCs are delivering maximum velocity.

In Fig. 30, the highest error for the reach position are $10.2[\mathrm{~mm}]$ for the main arm, $4.4[\mathrm{~mm}]$ for the upper guide arm, and $3.9[\mathrm{~mm}]$ for the lower guide arm.

The power consumptions of all elements (components) of the SCCs are plotted in Fig. 31, and in Fig. 26 the Sankey diagram is illustrating the energy distri- 

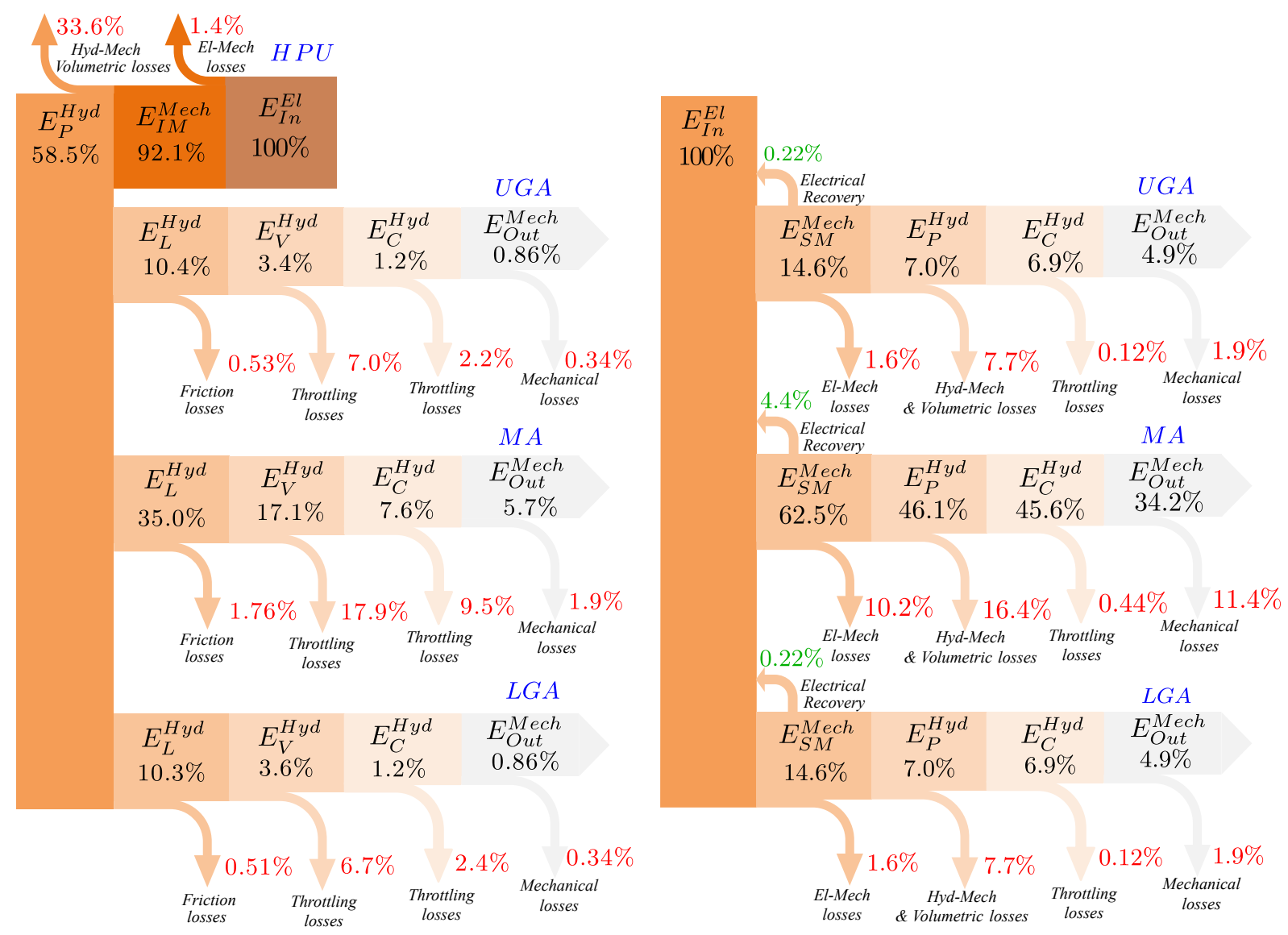

Figure 26: Sankey diagrams showing the energy distribution from electrical input to mechanical output: (left) benchmark system; (right) self-contained system.

bution from electrical input to mechanical output together with the following losses:

- Servo-motor - electric and mechanical losses (copper, Eddy current, hysteresis and viscous friction)

- Hydraulic pump - volumetric losses (leakage) eq. (14) and hydro-mechanical losses (friction) eq. (15)

- Load-holding valves: throttling losses eq. (71)

The average electro-hydraulic efficiency when considering the SCCs separately is $62.8 \%$ for the main arm and $42.7 \%$ for the guide arms.

The input power when the arms extend into the fingerboard (Fig. 31 between 31-52 [s]), is for the MA $-1.06[k W]$ at the highest, meaning that up to $1.06[k W]$ can be recovered, i.e., shared with the two GAs that are consuming $1.50[k W]$ each at its maximum. When the arms retract the power consumption is for the MA $5.86[k W]$ and for each of the GAs $0.49[k W]$.

\subsection{Energy Comparison}

In Fig. 32, the overall power and energy consumption of the benchmark system and self-contained system are compared. The energy saving potential using selfcontained electro-hydraulic cylinders versus centralized valve-controlled cylinders is $83.44 \%$.

Moreover, the total consumption of the selfcontained system is highlighted in Fig. 33, comparing the electric power and the energy consumption when energy recovery is applied or not for the considered system. From Fig. 33, it is clear that by enabling energy sharing between the main arm's SCC and the guide arm's SCCs, the overall energy consumption is improved by $6 \%$. However, if pumps with a better efficiency were available (e.g., a constant hydromechanical efficiency of $90 \%$ ) energy recovery would also be enabled for the guide arms SCCs, resulting in $45 \%$ less energy consumption compared to the considered self-contained cylinders with higher simulated pump losses. 


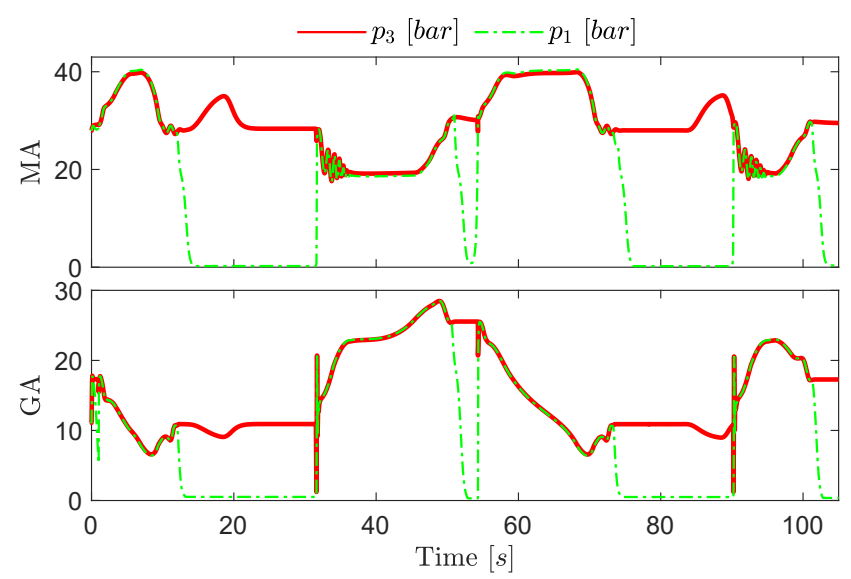

Figure 27: SCC's high pressures: (red) piston-side chamber; (green) pump supply.

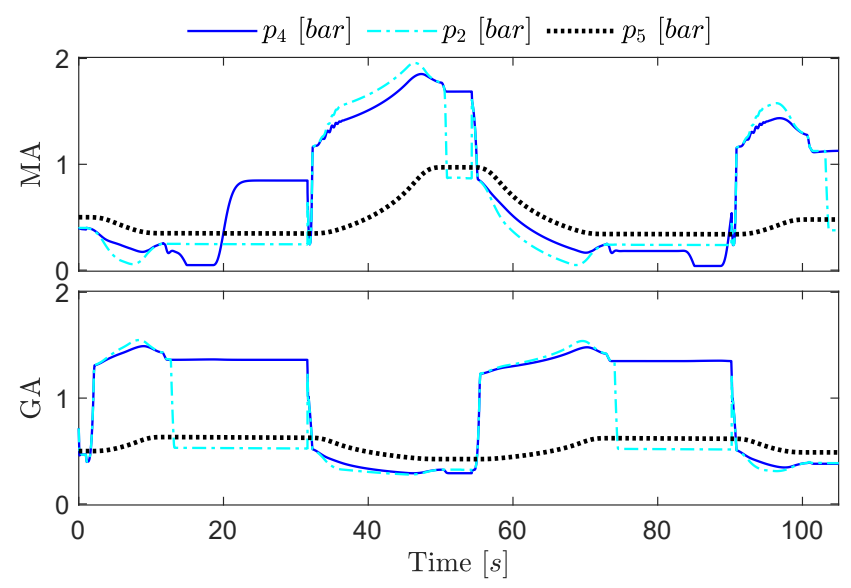

Figure 28: SCC's low pressures: (blue) rod-side chamber; (light blue) pump's suction-side; (black) accumulator.

\section{Discussion}

For the considered case-study, both the benchmark system and the self-contained system can follow the desired motion profile with acceptable position errors for the reach arms that are moving synchronously. The self-contained system has approximately $37 \%$ lower maximum position error. Moreover, this section discusses the energy saving potential and some practical challenges that must be considered in future works.

\subsection{Energy Saving Potential}

When considering the power from the mechanical system, and assuming 100\% efficient energy recovery, there is a potential for the considered offshore drilling application to regenerate $27.5 \%$ during the operational sequence. However, due to the hydro-mechanical losses of the hydraulic axial piston machine (65-92\% depending on the rotational speed and pressure drop across

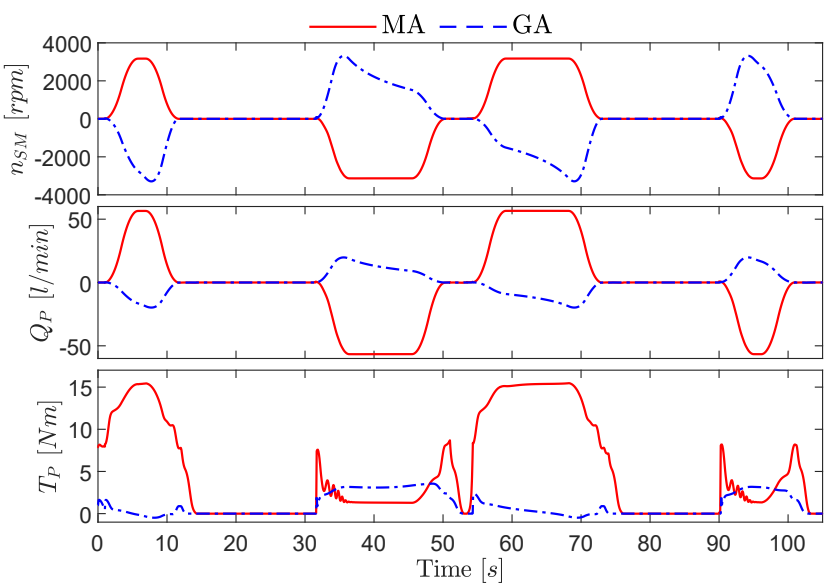

Figure 29: Performance of motor-pump unit: (top) rotational speed of the servo-motors; (middle) supplied flow to the cylinders; (bottom) torque demand of the pumps.

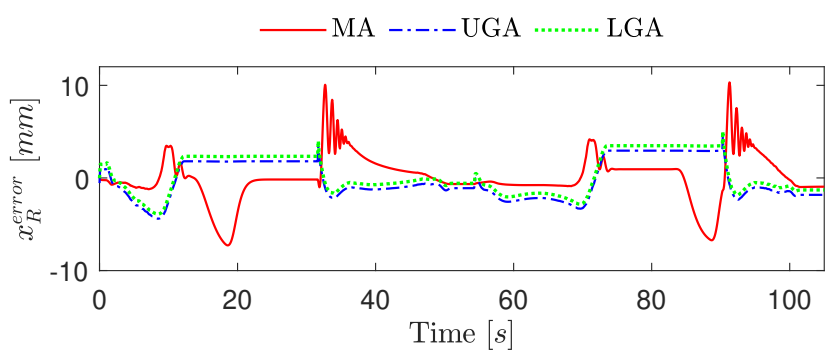

Figure 30: Reach arms position error using SCCs.

the pump), the potential power from the mechanical system is dissipating in the hydraulic machine. Consequently, only $6 \%$ of the total energy (when considering the energy consumption of the reach motion separately) can potentially be recovered, compared to $45 \%$, if a hydraulic machine with a constant hydromechanical efficiency of $90 \%$ is used.

Compared to the benchmark system representing the hydraulic actuation system used today, applying the considered self-contained cylinders instead of centralized valve-controlled cylinders to drive the reach arms, the energy saving potential is $83.44 \%$ without affecting the system's performance (e.g., the position tracking results even better). Furthermore, applying more efficient pumps to the self-contained system results in an energy saving potential of $91.1 \%$, and $88.33 \%$ when considering a more efficient pump for the benchmark system as well. The superior energy efficiency of the self-contained system is also due the "power on demand" capability: when the cylinders are idling (i.e., when the PRM moves between the $\mathrm{WC}$ and $\mathrm{FB}$ ), then the passive load-holding valves are activated and the electric-drive is switched off. Conversely, the hydraulic power unit of the benchmark system is always running to maintain a constant supply pressure. Also, us- 


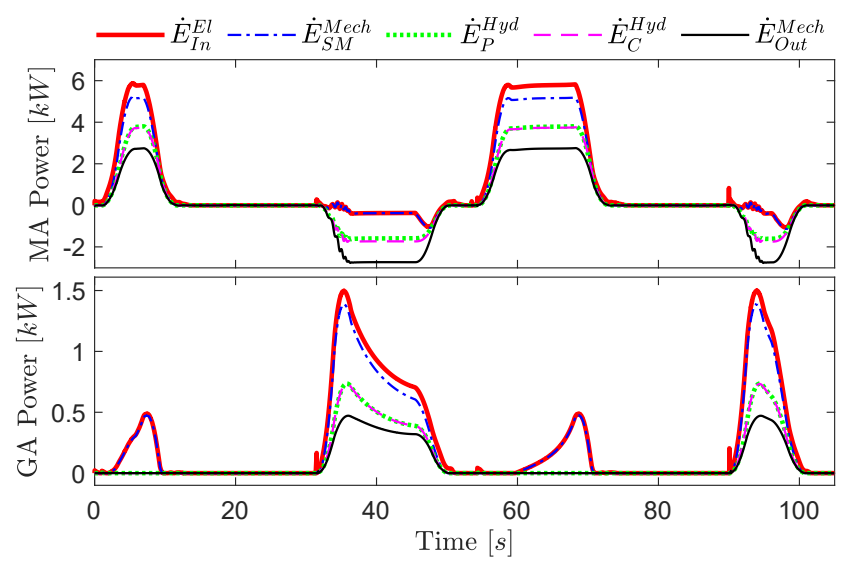

Figure 31: Power consumption of the main arm and guide arms SCCs.
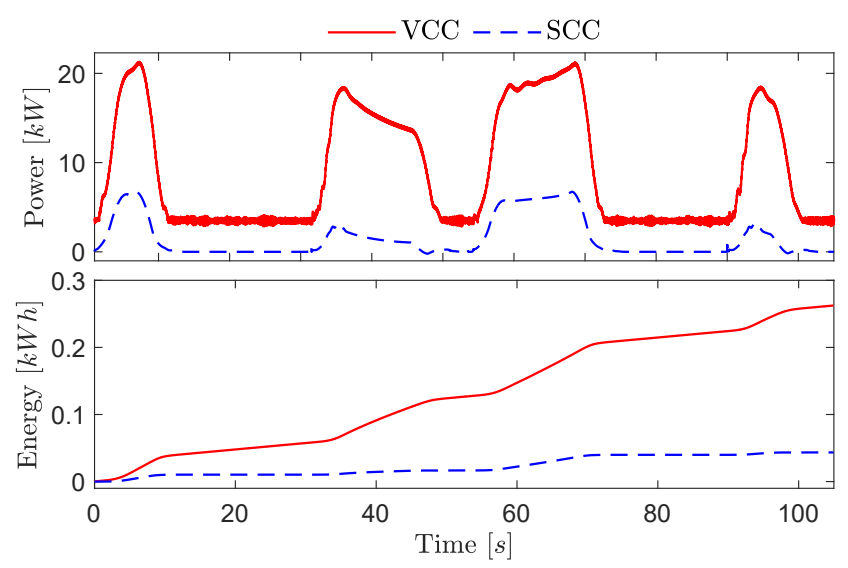

Figure 32: Energy comparison between benchmark system and self-contained system.

ing pilot-operated check valves as load-holding valves is much more energy efficient since flow throttling is almost negligible during motion. This is not the case for the counter-balance valves that waste approximately $134[k J]$ to enable the main arm cylinder to retract, while the SCC can regenerate energy.

\subsection{Challenges}

The scissor mechanism used in the main arm introduces high force peaks in the inner position when accelerating or decelerating. Consequently, the desired dynamic response of the actuation system is a tradeoff between cost and motion cycle time. Higher accelerations require an electric-drive with higher torque, and current limits, while the reaction force acting on the hydraulic cylinder will require a larger rod diameter due to the buckling factor criterion. Hence, designing the actuation system for the maximum load results in a non-optimal solution because of the oversized cylinder (due to the buckling safety factor) and

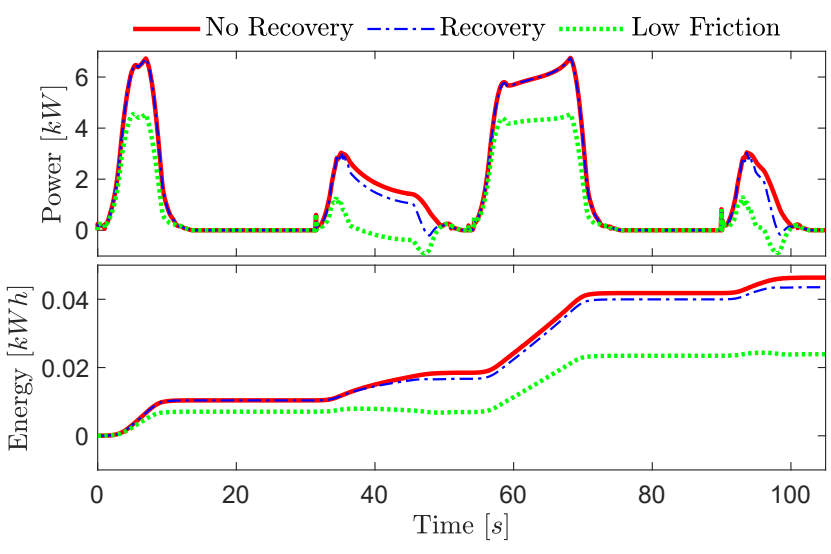

Figure 33: Comparison of the total energy consumption of the self-contained system without and with energy recovery, and with increased efficiency of the pump.

the high friction pump (during the operational load cycle, the required cylinder pressure is low, and hydraulic pumps, in general, have low hydro-mechanical efficiency when the pressure drop across the pump is low at high speed). Furthermore, energy efficiency may be further improved by designing the application so that the relation between actuator pressures and pump efficiency is optimal.

Currently, the motor drivers (frequency converters) of the $\mathrm{AC}$ drivetrains are located away from the machine. For each drivetrain, there is one electric power cable between the driver located in a centralized control-cabinet and the electric motor. In the proposed layout, as seen in Fig. 12, the motor drivers are located on the machine close to the actuator and there is only one power cable interfacing with the machine. Furthermore, on the machine, there is a common DC bus shared between the individual DC to AC inverters. This solution has the potential to save much space on the rig, and there will be fewer cables on the machine, compared to using a centralized control-cabinet. However, in explosive environments (Ex), such as on a drilling rig, all components need to be ATEX certified according to European Commission (2014). Consequently, the inverters (that today are not available for Ex environments) need to be located in ATEX certified junction boxes that take some extra space.

Furthermore, the AC drivetrains used today consist of induction motors that are well proved for the offshore end Ex environment. In SCCs the permanent magnet synchronous motors are preferred, mainly because of the superior power density, better efficiency, and controllability, compared to IMs.

Finally, the size and weight of the actuator itself (i.e., the cylinder) will increase using the self-contained concept compared to the conventional system. An example 


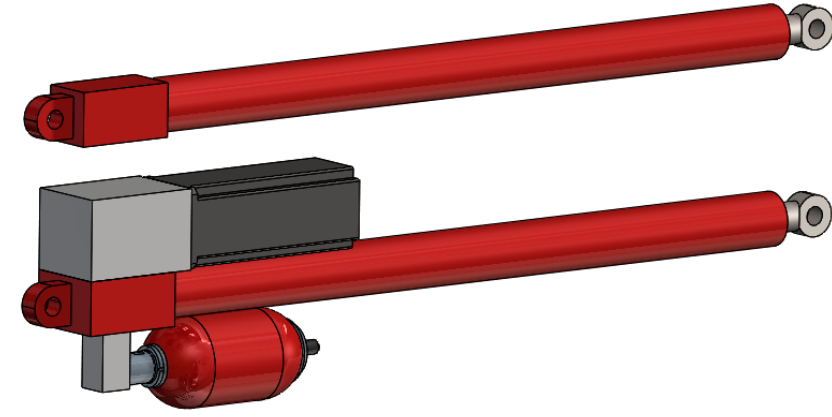

Figure 34: Size comparison - main arm cylinder (simplified CAD models).

is illustrated in Fig. 34 where the main arm's SCC is compared against the VCC using the same cylinder dimensions, when selecting the servo-motor, pump, and auxiliary-valves according to Table 6 .

Depending on the application, it may be challenging to install the SCC without doing re-design of the mechanical system. Hence, the whole machine design should be optimized around the SCC system when designing new applications.

\section{Conclusion}

This paper presents a simulation study to identify the energy saving potential when self-contained electrohydraulic cylinders are applied to an offshore pipe racking machine. This approach is an alternative to conventional valve-controlled cylinders used nowadays. To have a fair comparison between the energy consumption of the benchmark system and the new selfcontained system, both actuation systems have been designed based on the same requirements identified from an inverse dynamic analysis of the considered case-study. Numerical models representing all dominating loss elements of the actuation systems, from electrical input to the desired motion of the mechanical system, are considered.

This paper proposes an actuation system consisting of three self-contained cylinders that can share energy. Due to the "power on demand" capability, the cancellation of the throttling losses, and the opportunity to recover energy in motoring quadrants, the self-contained system demonstrates a superior energy efficiency compared to the benchmark system without affecting the system's performance. For the selected driving cycle, the benchmark system consumes $0.26[k W h]$ of electrical energy, while the self-contained system consumes $0.044[k W h]$ (i.e., $83.44 \%$ less energy) if ideal energy sharing is assumed.

This result suggests that potential for significant energy savings exists when using the proposed self- contained system for actuating the reach arms of the pipe racking machine. On an offshore drilling rig, reduced electric energy consumption will result in reduced consumption of fossil fuel of the diesel generators supplying the offshore installation with electricity. Additionally, by introducing the proposed actuation system that is self-sufficient and completely sealed, offshore mechatronic applications can reduce the risk of oil pollution to the ocean environment when compared to using centralized hydraulic power units.

\section{Acknowledgments}

The research presented in this paper has received funding from the Norwegian Research Council, SFI Offshore Mechatronics, project number 237896.

\section{Nomenclature}

\begin{tabular}{llr}
\hline Symb. & Description & Unit \\
\hline$V_{L}$ & RMS voltage & {$[\mathrm{V}]$} \\
$A_{\text {peak }}$ & Peak amplitude & {$[\mathrm{V}]$} \\
$\mathrm{V}_{s}^{s}$ & Stator-voltage & {$[\mathrm{V}]$} \\
$T_{32}$ & Clarke transformation & \\
$\dot{\mathrm{I}}_{s}^{s}$ & Stator-current & {$[\mathrm{A}]$} \\
$\Psi_{r 1}^{s}$ & Rotor fluxes cage 1 & {$[\mathrm{Vs}]$} \\
$\Psi_{r 2}^{s}$ & Rotor fluxes cage 2 & {$[\mathrm{Vs}]$} \\
$j$ & Imaginary unit & \\
$\omega_{m}$ & Mech. angular velocity & {$\left[\frac{\mathrm{rad}}{\mathrm{s}}\right]$} \\
$\omega_{r}$ & Electrical angular velocity & {$\left[\frac{\mathrm{rad}}{\mathrm{s}}\right]$} \\
$T_{e m}$ & Electromagnetic torque & {$[\mathrm{Nm}]$} \\
$p$ & Number of poles & {$[-]$} \\
$L_{r 1}$ & Rotor inductance cage 1 & {$[\mathrm{H}]$} \\
$L_{r 2}$ & Rotor inductance cage 2 & {$[\mathrm{H}]$} \\
$L_{m}$ & Mutual inductance & {$[\mathrm{H}]$} \\
$L_{\lambda}$ & Total inductance & {$[\mathrm{H}]$} \\
$T_{P}$ & Pump torque & {$[\mathrm{Nm}]$} \\
$B_{f}$ & Viscous friction coefficient & {$\left[\frac{\mathrm{Nms}}{\mathrm{rad}}\right]$} \\
$J_{t o t}$ & Combined inertia & {$\left[\frac{\mathrm{rad}}{\mathrm{s}}\right]$} \\
$i_{a, b, c}$ & Stator currents & {$[\mathrm{V}]$} \\
$T_{23}$ & Inv. Clarke transformation & \\
$a_{i}$ & State space constant & {$[\mathrm{W}]$} \\
$F_{R}$ & Force delivered to the MBS & {$[\mathrm{N}]$} \\
$F_{C}$ & Hydraulic cylinder force & {$[\mathrm{N}]$} \\
$A_{A}$ & Piston area of the cylinder & {$\left[\mathrm{m}^{2}\right]$} \\
$A_{B}$ & Annulus area of the cylinder & {$\left[\mathrm{m}^{2}\right]$} \\
$p_{i}$ & Hydraulic pressure & {$[\mathrm{Pa}]$} \\
$\dot{p}_{i}$ & Pressure buildup & {$\left[\frac{\mathrm{Pa}}{\mathrm{s}}\right]$} \\
\hline & Continued on next column & \\
\hline & & \\
& & \\
& & \\
& & \\
& &
\end{tabular}




\section{Continued from previous column}

\begin{tabular}{|c|c|c|}
\hline Symb. & Description & Unit \\
\hline$p_{c r}$ & Crack pressure & {$[P a]$} \\
\hline$Q_{V i}$ & Flow through valve & {$\left[\frac{m^{3}}{s}\right]$} \\
\hline$k_{S}$ & Flow loss gain supply line & {$[-]$} \\
\hline$k_{R}$ & Flow loss gain return line & {$\left[\frac{m^{3}}{s}\right]$} \\
\hline$p_{L S}$ & Load-sensing pressure & {$[P a]$} \\
\hline$v_{C}$ & Cylinder velocity & {$\left[\frac{m}{s}\right]$} \\
\hline$V_{i}$ & Volume & {$\left[m^{3}\right]$} \\
\hline$B_{i}$ & Effective bulk modulus & {$[\mathrm{Pa}]$} \\
\hline$x_{C}$ & Effective cylinder displacement & {$[m]$} \\
\hline$h_{C}$ & Max piston displacement & {$[m]$} \\
\hline$\beta_{0}$ & Bulk modulus & {$[P a]$} \\
\hline$\kappa_{\text {air }}$ & Adiabatic air constant & {$[-]$} \\
\hline$p_{\text {atm }}$ & Atmospheric pressure & {$[P a]$} \\
\hline$\eta_{\text {air }}$ & Volumetric air constant & {$[\%]$} \\
\hline$\Delta_{p_{V}}$ & Pressure drop across the valve & {$[P a]$} \\
\hline$k_{V}$ & Flow constant of the valve & {$\left[\frac{m^{3}}{s \sqrt{P a}}\right]$} \\
\hline & Effective valve opening & {$[-]$} \\
\hline$G_{V}(s)$ & Valve dynamic of the PDCV & {$[-]$} \\
\hline$\omega_{V}$ & Natural frequency of the PDCV & {$\left[\frac{\mathrm{rad}}{\mathrm{s}}\right]$} \\
\hline$\zeta_{V}$ & Damping ratio of the PDCV & {$[-]$} \\
\hline$p_{c r}$ & Cracking pressure of the valve & {$[\mathrm{Pa}]$} \\
\hline$p_{f o}$ & Pressure to fully open the valve & {$[\mathrm{Pa}]$} \\
\hline$\alpha_{i}$ & Pilot ratio of the $\mathrm{CBV}$ & {$[P a]$} \\
\hline$p_{x}$ & Pilot pressure of the CBV & {$[\mathrm{Pa}]$} \\
\hline$L_{s}$ & Stator inductance & {$[H]$} \\
\hline$R_{s}$ & Stator resistance & {$[\mathrm{Ohm}]$} \\
\hline$\Psi_{R}$ & Rotor flux & {$[V s]$} \\
\hline$E^{s}$ & Back emf & {$[V]$} \\
\hline$\theta$ & Flux angle & {$[\mathrm{rad}]$} \\
\hline$K$ & Space vector scaling constant & {$[-]$} \\
\hline$i_{q}$ & Torque generating current & {$[A]$} \\
\hline$V_{A C_{0}}$ & AC pre-charge pressure & {$[P a]$} \\
\hline$C_{i}$ & Hydraulic capacitance & {$\left[\frac{P a}{m^{3}}\right]$} \\
\hline$C_{d}$ & Discharge coefficient & {$[-]$} \\
\hline$\xi_{N F}$ & Poppet lift normal flow & {$[-]$} \\
\hline$\xi_{R F}$ & Poppet lift reverse flow & {$[-]$} \\
\hline$A_{S}$ & Poppet seat area & {$\left[m^{2}\right]$} \\
\hline$F_{S_{0}}$ & Spring's pre-load force & {$[N]$} \\
\hline$k_{S}$ & Spring stiffness & {$\left[\frac{N}{m}\right]$} \\
\hline$A_{x}$ & Pilot stage area & {$\left[m^{2}\right]$} \\
\hline
\end{tabular}

\section{A. Appendices}

\section{A.1. Benchmark System}

The following equations represent the numerical model of the hydraulic power supply and the valve-controlled cylinders as depicted in Fig. 8 and 10.

$$
\begin{gathered}
\frac{d \dot{\mathrm{I}}_{s}^{s}}{d t}=\left(a_{32 b}+a_{32 a} j \omega_{r}\right) \Psi_{r 2}^{s}+a_{21} \Psi_{r 1}^{s}+a_{33} \dot{\mathrm{I}}_{s}^{s} \\
+b_{3} \mathrm{~V}_{s}^{s}+\left(a_{31 b}+a_{31 a} j \omega_{r}\right) \Psi_{r 1}^{s} \\
\mathrm{~V}_{s}^{s}=\left[\begin{array}{l}
\operatorname{Re}\left(v_{\alpha}\right) \\
\operatorname{Im}\left(v_{\beta}\right)
\end{array}\right]=\left[\begin{array}{l}
u_{a} \\
u_{b} \\
u_{c}
\end{array}\right] T_{32}
\end{gathered}
$$$$
\frac{d \Psi_{r 1}^{s}}{d t}=\left(a_{11}+j \omega_{r}\right) \Psi_{r 1}^{s}+a_{12} \Psi_{r 2}^{s}+a_{13} \dot{\mathrm{I}}_{s}^{s}
$$$$
\frac{d \Psi_{r 2}^{s}}{d t}=\left(a_{22}+j \omega_{r}\right) \Psi_{r 2}^{s}+a_{21} \Psi_{r 1}^{s}+a_{23} \dot{\mathrm{I}}_{s}^{s}
$$$$
T_{e m}=\operatorname{Im}\left(\Psi_{r 1}^{s} \dot{\mathrm{I}}_{s}^{s}\right) \frac{p L_{r 2} L_{m}}{3 L_{\lambda}}+\operatorname{Im}\left(\Psi_{r 2}^{s} \dot{\mathrm{I}}_{s}^{s}\right) \frac{p L_{r 1} L_{m}}{3 L_{\lambda}}
$$$$
\frac{d \omega_{m}}{d t}=\frac{T_{e m}-T_{P}-B_{f} \omega_{m}}{J_{t o t}}
$$$$
T_{P}=\frac{D_{P} \Delta_{p, i}}{2 \pi}+T_{S} \operatorname{sign}\left(\omega_{m}\right)
$$$$
\omega_{r}=\frac{p}{2} \omega_{m}
$$

$$
\left[\begin{array}{c}
i_{a} \\
i_{b} \\
i_{c}
\end{array}\right]=\left[\begin{array}{l}
\operatorname{Re}\left(i_{\alpha}\right) \\
\operatorname{Im}\left(i_{\beta}\right)
\end{array}\right] T_{23}=\mathrm{I}_{s}^{s} T_{23}
$$

$$
F_{R}^{V C C}=\underbrace{p_{A} A_{A}-p_{B} A_{B}}_{F_{C}}-F_{f}
$$

$$
\dot{p}_{P}=\frac{\beta_{P}\left(Q_{P}-Q_{R V}\right)}{V_{P_{0}}}
$$

$$
Q_{P}=D_{P} \omega_{m}-Q_{S} \operatorname{sign}\left(\omega_{m}\right)
$$

$$
\dot{p}_{A 1}=\frac{\beta_{A 1}\left(Q_{V_{I n}}-Q_{C V_{A}}+Q_{P V_{A}}\right)}{V_{A 1_{0}}}
$$

$$
\dot{p}_{A}=\frac{\beta_{A}\left(Q_{C V_{A}}-A_{A} v_{C}-Q_{P V_{A}}\right)}{A_{A} x_{C}+V_{A_{0}}}
$$

$$
\dot{p}_{B 1}=\frac{\beta_{B 1}\left(Q_{V_{\text {Out }}}-Q_{C V_{B}}+Q_{P V_{B}}\right)}{V_{B 1_{0}}}
$$




$$
\begin{aligned}
& \dot{p}_{B}=\frac{\beta_{B}\left(Q_{C V_{B}}+A_{B} v_{C}-Q_{P V_{B}}\right)}{A_{B}\left(h_{C}-x_{C}\right)+V_{B_{0}}} \\
& \dot{p}_{S}=\frac{\beta_{S}\left(\sqrt{\frac{1}{k_{S}} \frac{2}{\rho}\left|p_{P}-p_{R}\right|}-Q_{V_{I n}}\right)}{V_{S_{0}}} \\
& \dot{p}_{R}=\frac{\beta_{R}\left(Q_{V_{\text {Out }}}-\sqrt{\frac{1}{k_{R}} \frac{2}{\rho}\left|p_{R}-p_{T}\right|}\right)}{V_{R_{0}}} \\
& p_{C}=\left\{\begin{array}{cc}
p_{L S}+p_{c r C}^{P C}, & p_{c r C}^{P C} \leq\left(p_{S}-p_{L S}\right) \\
p_{S}-p_{L S}, & 0<\left(p_{S}-p_{L S}\right)<p_{c r C}^{P C} \\
p_{L S}, & \left(p_{S}-p_{L S}\right) \geq 0
\end{array}\right. \\
& p_{L S}=\left\{\begin{array}{cc}
p_{A 1}, & \xi_{V}<0 \\
p_{R}, & \xi_{V}=0 \\
p_{B 1}, & \xi_{V}>0
\end{array}\right. \\
& \beta_{i}=\frac{1}{\frac{1}{\beta_{0}}-\frac{1}{\kappa_{a i r}\left(p_{i}+p_{a t m}\right)\left(\frac{\eta_{a i r}-1}{\eta_{a i r}\left(\frac{p_{a t m}}{p_{i}-p_{a t m}}\right) \frac{1}{\kappa_{a i r}}}-1\right)}} \\
& Q_{V}=k_{V} \xi_{V} \sqrt{\left|\Delta_{p_{V}}\right|} \operatorname{sign}\left(\Delta_{p_{V}}\right) \\
& G_{V}(s)=\frac{\xi_{V}}{u_{V}}=\frac{\omega_{V}^{2}}{s^{2}+2 \omega_{V} \zeta_{V} s+\omega_{V}^{2}} \\
& \xi_{C V}=\frac{\Delta_{p_{C V}}-p_{c r, C V}}{p_{f o, C V}} \\
& \xi_{P V}=\frac{p_{I n, P V}+\alpha_{i} p_{x}-p_{c r, P V}}{p_{f o, P V}}
\end{aligned}
$$

\section{A.2. Self-Contained System}

The following equations represent the numerical model of the self-contained electro-hydraulic cylinders as depicted in Fig. 11.

$$
\begin{gathered}
L_{s} \frac{d \dot{\mathrm{I}}_{s}^{s}}{d t}=\mathrm{V}_{s}^{s}-R_{s} \dot{\mathrm{I}}_{s}-\underbrace{j \omega_{r} \Psi_{R} e^{j \theta}}_{E^{s}} \\
T_{e m}=\frac{3 p}{2 K^{2}} \operatorname{Im}\left(\Psi_{R} i_{q}\right)
\end{gathered}
$$

$$
\begin{gathered}
J_{t o t} \frac{d \omega_{m}}{d t}=\frac{3 p}{2 K^{2}} T_{e m}-T_{P} \\
F_{R}^{S C C}=\underbrace{p_{3} A_{A}-p_{4} A_{B}}_{F_{C, i}}-F_{f, i}
\end{gathered}
$$

$$
\begin{gathered}
\dot{p}_{1}=\frac{\beta_{1}\left(Q_{P}+Q_{F C_{1}}-Q_{L H_{1}}-Q_{R V_{1}}-Q_{A c_{1}}\right)}{V_{1_{0}}} \\
\dot{p}_{2}=\frac{\beta_{2}\left(-Q_{P}-Q_{C V_{1}}+Q_{A c_{2}}-Q_{L H_{2}}-Q_{R V_{2}}\right)}{V_{2_{0}}}
\end{gathered}
$$

$$
\dot{p}_{3}=\frac{\beta_{3}\left(Q_{L H_{1}}-A_{A} v_{C}-Q_{R V_{3}}+Q_{A c_{3}}-Q_{C V_{3}}\right)}{V_{3_{0}}+A_{A} x_{C}}
$$

$$
\dot{p}_{4}=\frac{\beta_{4}\left(Q_{L H_{2}}+A_{B} v_{C}-Q_{R V_{4}}+Q_{A c_{4}}-Q_{C V_{4}}\right)}{V_{4_{0}}+A_{B}\left(h_{C}-x_{C}\right)}
$$

$$
\dot{p}_{5}=\frac{Q_{R V_{1-4}}+Q_{E V}-Q_{F C_{1-2}}-Q_{A c_{1-4}}}{C_{5}}
$$

$$
\dot{p}_{9}=\frac{\beta_{9} Q_{E V}}{V_{9_{0}}}
$$$$
C_{5}=\frac{V_{5_{0}}}{\beta_{5}}+\frac{V_{A C_{0}}}{\kappa_{a i r}} \frac{p_{A C_{0}} \frac{1}{\kappa_{a i r}}}{p_{5}^{\frac{\kappa_{a i r}+1}{\kappa_{a i r}}}}
$$

$$
\begin{gathered}
Q_{P O C V}=C_{d} \pi d \xi_{j} \sqrt{\frac{2}{\rho}\left|\Delta_{p}\right|} \operatorname{sign}\left(\Delta_{p}\right) \\
\xi_{N F}=\frac{\left(p_{\text {In }}-p_{O u t}\right) A_{S}-F_{S}}{k_{S}}
\end{gathered}
$$

$\xi_{R F}=\frac{\left(p_{x}-p_{I n}\right) A_{x}+\left(p_{I n}-p_{O u t}\right) A_{S}-F_{S_{0}}}{k_{S}}$

$$
Q_{V}=\left\{\begin{array}{cc}
0, & \text { if } p_{\text {In }}<p_{\text {Out }}+p_{c} \\
k_{V}\left(p_{\text {In }}-p_{\text {Out }}-p_{c}\right), & \text { if } p_{\text {In }} \geq p_{\text {Out }}+p_{c}
\end{array}\right.
$$




\section{References}

Bak, M. K. Model Based Design of Electro-Hydraulic Motion Control Systems for Offshore Pipe Handling Equipment. Ph.D. thesis, University of Agder, 2014. doi:10.16373/j.cnki.ahr.150049.

Bak, M. K. and Hansen, M. R. Model based design optimization of operational reliability in offshore boom cranes. International Journal of Fluid Power, 2013. 14(3). doi:10.1080/14399776.2013.10801413.

European Commission. Directive 2014/34/EU of the European Parliament and of the Council. Technical report, Official Journal of the European Union L96, 2014.

Hagen, D., Padovani, D., and Choux, M. Design and Implementation of Pressure Feedback for LoadCarrying Applications With Position Control [Accepted]. In The Sixteenth Scandinavian International Conference on Fluid Power. 2019.

Hagen, D., Padovani, D., and Ebbesen, M. K. Study of a Self-Contained Electro-Hydraulic Cylinder Drive. 2018 Global Fluid Power Society PhD Symposium, GFPS 2018, 2018. doi:10.1109/GFPS.2018.8472360.

Hagen, D., Pawlus, W., Ebbesen, M. K., and Andersen, T. O. Feasibility Study of Electromechanical Cylinder Drivetrain for Offshore Mechatronic Systems. Modeling, Identification and Control, 2017. 38(2). doi:10.4173/mic.2017.2.2.

Harnefors, L. Control of Variable-Speed Drives. Mälardalen University, 2003.

Ketelsen, S., Padovani, D., Andersen, T., Ebbesen, M., and Schmidt, L. Classification and Review of PumpControlled Differential Cylinder Drives. Energies, 2019. 12(7). doi:10.3390/en12071293.

Ketelsen, S., Schmidt, L., Donkov, V., and Andersen, T. Energy saving potential in knuckle boom cranes using a novel pump controlled cylinder drive. Modeling, Identification and Control, 2018. 39(2). doi:10.4173/mic.2018.2.3.

Kjelland, M. B. Offshore Wind Turbine Access Using Knuckle Boom Cranes. Ph.D. thesis, University of Agder, 2016.
Krause, P., Wasynczuk, O., and Sudhoff, S. Analysis of Electric Machinery. IEEEß Press, 2002.

Michel, S. and Weber, J. Energy-efficient electrohydraulic companct drives for low power applications. ASME/BATH 2012 Symposium on Fluid Power and Motion Control, 2012.

Padovani, D., Ketelsen, S., Hagen, D., and Schmidt, L. A Self-Contained Electro-Hydraulic Cylinder with Passive Load-Holding Capability. Energies, 2019. 12(2):292. doi:10.3390/en12020292.

Pawlus, W., Choux, M., and Hansen, M. R. Hydraulic vs. electric: A review of actuation systems in offshore drilling equipment. Modeling, Identification and Control, 2016. 37(1). doi:10.4173/mic.2016.1.1.

Ristic, M. and Wahler, M. Electrification of Hydraulics Opens New Ways for Intelligent Energy-Optimized Systems. In 11th International Fluid Power Conference. 2018.

Schmidt, L., Groenkjaer, M., Pedersen, H. C., and Andersen, T. O. Position Control of an OverActuated Direct Hydraulic Cylinder Drive. Control Engineering Practice, 2017. 64. doi:10.1016/j.conengprac.2017.04.003.

Schmidt, L., Roemer, D. B., Pedersen, H. C., and Andersen, T. O. Speed-Variable Switched Differential Pump System for Direct Operation of Hydraulic Cylinders. In ASME/BATH 2015 Symposium on Fluid Power and Motion Control. 2015. doi:10.1115/FPMC2015-9575.

Sørensen, J. K. Reduction of Oscillations in Hydraulically Actuated Knuckle Boom Cranes. Ph.D. thesis, University of Agder, 2016.

Stecki, J. S. and Garbacik, A. Design and Steady-state Analysis of Hydraulic Control Systems. Fluid Power Net Publications, 2002.

Williamson, C. and Ivantysynova, M. The effect of pump efficiency on displacement-controlled actuator systems. In Tenth Scandinavian International Conference on Fluid Power, Tampere, Finland. 2007. 